\title{
Effect of sea breeze circulation on aerosol mixing state and radiative properties in a desert setting
}

\author{
Yevgeny Derimian ${ }^{1}$, Marie Chö̈l $^{2}$, Yinon Rudich ${ }^{3}$, Karine Deboudt $^{4}$, Oleg Dubovik $^{1}$, Alexander Laskin ${ }^{5}$, \\ Michel Legrand $^{1}$, Bahaiddin Damiri ${ }^{1,6}$, Ilan Koren ${ }^{3}$, Florin Unga ${ }^{1,2}$, Myriam Moreau ${ }^{2}$, Meinrat O. Andreae ${ }^{7,8}$, and \\ Arnon Karnieli ${ }^{9}$ \\ ${ }^{1}$ Laboratoire d'Optique Atmosphérique, UMR8518 CNRS, Universiteé de Lille 1, Villeneuve d'Ascq, 59655, France \\ ${ }^{2}$ Laboratoire de Spectrochimie Infrarouge et Raman, Université de Lille 1, Villeneuve d'Ascq, 59655, France \\ ${ }^{3}$ Department of Earth and Planetary Sciences, Weizmann Institute of Science, Rehovot 76100, Israel \\ ${ }^{4}$ Laboratoire de Physico-Chimie de l'Atmosphère, Université du Littoral Côte d'Opale, Dunkirk, 59140, France \\ ${ }^{5}$ Department of Chemistry, Purdue University, West Lafayette, IN 47907-2084, USA \\ ${ }^{6}$ Cimel Electronique, Paris, 75011, France \\ ${ }^{7}$ Biogeochemistry Department, Max Planck Institute for Chemistry, P.O. Box 3060, 55020 Mainz, Germany \\ ${ }^{8}$ Department of Geology, King Saud University, P.O. Box 2455, 11451 Riyadh, Saudi Arabia \\ ${ }^{9}$ Remote Sensing Laboratory, Jacob Blaustein Institutes for Desert Research, Ben-Gurion University of the Negev, \\ Sede Boker 84990, Israel
}

Correspondence to: Yevgeny Derimian (yevgeny.derimian@univ-lille1.fr)

Received: 1 December 2016 - Discussion started: 8 February 2017

Revised: 21 June 2017 - Accepted: 10 July 2017 - Published: 25 September 2017

\begin{abstract}
Chemical composition, microphysical, and optical properties of atmospheric aerosol deep inland in the Negev Desert of Israel are found to be influenced by daily occurrences of sea breeze flow from the Mediterranean Sea. Abrupt increases in aerosol volume concentration and shifts of size distributions towards larger sizes, which are associated with increase in wind speed and atmospheric water content, were systematically recorded during the summertime at a distance of at least $80 \mathrm{~km}$ from the coast. Chemical imaging of aerosol samples showed an increased contribution of highly hygroscopic particles during the intrusion of the sea breeze. Besides a significant fraction of marine aerosols, the amount of internally mixed marine and mineral dust particles was also increased during the sea breeze period. The number fraction of marine and internally mixed particles during the sea breeze reached up to $88 \%$ in the $\mathrm{PM}_{1-2.5}$ and up to $62 \%$ in the $\mathrm{PM}_{2.5-10}$ size range. Additionally, numerous particles with residuals of liquid coating were observed by SEM/EDX analysis. Ca-rich dust particles that had reacted with anthropogenic nitrates were evidenced by Raman microspectroscopy. The resulting hygroscopic particles can deliquesce at very low relative humidity. Our observations sug-
\end{abstract}

gest that aerosol hygroscopic growth in the Negev Desert is induced by the daily sea breeze arrival. The varying aerosol microphysical and optical characteristics perturb the solar and thermal infrared radiations. The changes in aerosol properties induced by the sea breeze, relative to the background situation, doubled the shortwave radiative cooling at the surface (from -10 to $-20.5 \mathrm{~W} \mathrm{~m}^{-2}$ ) and increased by almost 3 times the warming of the atmosphere (from 5 to $14 \mathrm{~W} \mathrm{~m}^{-2}$ ), as evaluated for a case study. Given the important value of observed liquid coating of particles, we also examined the possible influence of the particle homogeneity assumption on the retrieval of aerosol microphysical characteristics. The tests suggest that sensitivity to the coating appears if backward scattering and polarimetric measurements are available for the inversion algorithm. This may have an important implication for retrievals of aerosol microphysical properties in remote sensing applications. 


\section{Introduction}

Chemical composition and mixing state of atmospheric particles evolve during their transport in the atmosphere leading to changes in the aerosol optical properties and radiative effect. For instance, airborne mineral dust particles, which are often modeled as hydrophobic particles since they are originally composed of non-soluble chemical species, can be transformed into complex heterogeneous mixtures of nonreactive and reactive compounds (Dentener et al., 1996; Krueger et al., 2003, 2004; Falkovich et al., 2004; Laskin et al., 2005b). The appearance of secondary organics on the dust surface (Falkovich et al., 2004) and heterogeneous reactions between pollutants and components of dust can produce a deliquescent layer that favors water uptake by mineral dust (Usher et al., 2003; Laskin et al., 2005a). Also, laboratory experiments have shown that water adsorption can occur even on non-reactive surfaces of dust particles (Navea et al., 2010). Numerous field observations provide evidence of the presence of water-soluble inorganic ions such as sulfates and nitrates as dust coating material (Levin et al., 1996, 2005). Therefore, airborne mineral dust can be treated as a potential surface for heterogeneous chemistry (Usher et al., 2003), which can significantly alter its hygroscopic, morphological, and optical properties during atmospheric lifetime. In the case of ambient aerosols, when the changes occur in time and space, identification and evaluation of the physicochemical transformations and their influence on radiative properties can be particularly complex. In the current study, we show that a rather regular sea breeze phenomenon can be a test case for exploring how the mixing state of airborne particles changes under conditions of mixed air mass and varying relative humidity. During sea breeze intrusions inland, marine particles can mix with local pollutants in urban/industrial areas or with aeolian dust in arid regions and heterogeneous reactions can take place. The interactions can produce more complex atmospheric particles, with microphysical and optical properties that may be difficult to model. In our study, we focus on the variability in aerosol optical and physicochemical properties during sea breeze intrusions into the Negev Desert of Israel.

The Negev Desert is known to be generally influenced by airborne mineral dust, urban/industrial pollution, and marine aerosols (Maenhaut et al., 1997; Andreae et al., 2002; Sobanska et al., 2003; Karnieli et al., 2009). However, the influence of the daily sea breeze on the aerosol properties in the Negev Desert has not been studied so far. In this study, we explore the influence of penetrating marine air masses on the mixing state and hygroscopic properties of aerosol particles observed at Sede Boker, a desert site located $80 \mathrm{~km}$ away from the Mediterranean coast (the site is sometimes also referred to as Sde Boker). The dust at this site originates from either local or remote dust sources. The pollutants originate in the central and more polluted areas of Israel or are transported from eastern Europe (Andreae et al.,
2002; Karnieli et al., 2009; Maenhaut et al., 2014). While windblown desert dust affects the Negev Desert all year long with concentration peaking in spring and autumn, a maximum of the anthropogenic aerosols appears in the summertime (Derimian et al., 2006). Long-term observations at the site provide an extensive dataset of aerosol characteristics and origins. The regular intrusion of the sea breeze is now employed to elucidate of how the evolution of humid conditions accompanied with the intrusion of aged sea-salt and pollution aerosols modifies the mixing state of mineral dust and how this affects the aerosol radiative effect. To address this goal, we employ a multidisciplinary approach by utilizing a combination of comprehensive remote sensing observations coupled with in situ aerosol measurements and offline chemical imaging of atmospheric particles collected at the site. The comprehensive observations were conducted during summer of 2012. Chemical imaging of particles collected before and during sea breeze was carried out by offline scanning electron microscopy, X-ray microanalysis, and Raman microspectroscopy. Finally, effects of internally mixed particles on their optical properties and consequent implications for remote sensing algorithms are also discussed.

\section{Measurement site and meteorological conditions}

The Sede Boker site is located in the Negev Desert, in the southern part of Israel $\left(30^{\circ} 51^{\prime} \mathrm{N}, 34^{\circ} 47^{\prime} \mathrm{E}\right)$, and is remote from big cities and industrial areas. It is about $80 \mathrm{~km}$ inland from the Mediterranean Sea coast and $470 \mathrm{~m}$ above sea level. As a remote desert site for atmospheric aerosol observations, the Sede Boker site was established in 1995 as part of the AERONET network of sun/sky photometers and the ARACHNE program (e.g., Ichoku et al., 1999; Formenti et al., 2001; Andreae et al., 2002).

The main aerosol types that affect the site are local and long-range-transported mineral dust, transported pollutants, and marine particles. The air masses in the summer period originate from the northwest, bringing anthropogenic aerosols from densely populated areas of central Israel and from eastern Europe (Andreae et al., 2002). The transport of anthropogenic emissions is attributed to a persistent largescale synoptic condition that is characterized by a semipermanent low-pressure trough extending from the Persian Gulf to the Negev, while the diurnal variations of mixed layer depth in this time are driven by surface heat fluxes and by the daily sea breeze cycle (Dayan and Rodnizki, 1999). During the observation period in summer 2012, measurements from a local meteorological station showed generally northwesterly wind direction with a regular sea breeze presence in afternoon. Figure 1a shows that after about 14:00 UTC (local time is UTC + 3) the mean wind direction is relatively constant and the mean wind speed increases up to $8 \mathrm{~m} \mathrm{~s}^{-1}$. Despite that the average air temperature and relative humidity near the ground (Fig. 1c) show a smooth behavior, abrupt 


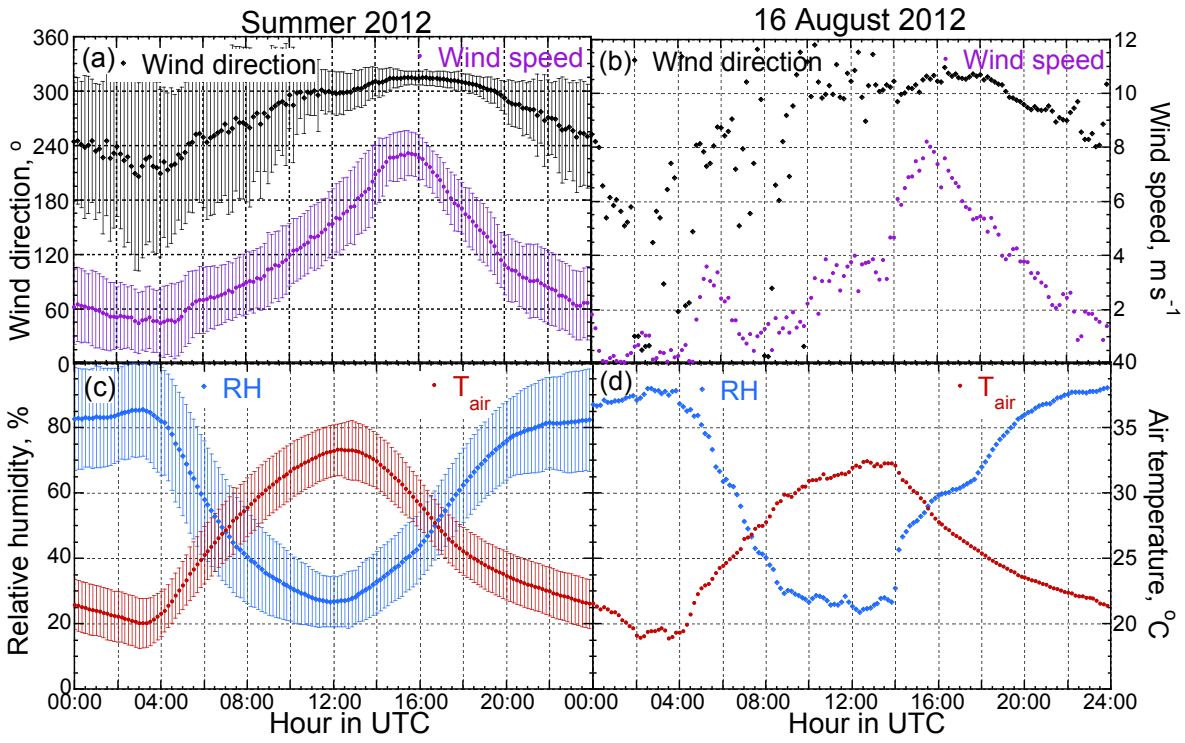

Figure 1. Mean diurnal variability in (a) wind direction and speed and (c) relative humidity and air temperature calculated from 3 months (June, July, August 2012); error bars correspond to \pm 1 standard deviation. Panels (b, d) show the diurnal cycle of the same variables for 16 August 2012.

changes can be clearly distinguished in observations for any single day when the sea breeze occurs. An example of a clear manifestation of the sea breeze arrival at 14:00 UTC is presented for 16 August (Fig. 1b, d), i.e., drop of temperature, quick rise of relative humidity, quick increase in wind speed accompanied by stabilized wind direction from northwest. Here, 16 August is the case study day when aerosol sampling before and during the sea breeze was analyzed. This specific day is selected for a comprehensive analysis and in-depth understanding of aerosol properties in the Negev Desert during the sea breeze phenomenon because the sampling conditions and the selected timing (i.e., start time, duration) were the most favorable on this day for discussing the variability in aerosol microphysical and chemical characteristics with respect to the variability in the optical measurements. We would also like to mention that the similar aerosol samplings (with and without sea breeze) were conducted on other days during the observation period and the compositional characteristics of particles were quite similar.

In addition to the local meteorological measurements, $24 \mathrm{~h}$ and 3-day backward trajectories are obtained using the HYSPLIT model for 16 August. The 3-day trajectories show a general northwest air mass origin (Fig. 2c) that is typical for the summer season and the $24 \mathrm{~h}$ trajectories show a change in direction of the near-ground air masses (red line for $10 \mathrm{~m}$ altitude) when the sea breeze reaches the site (Fig. 2a, b). Before reaching the measurement site, the air masses remain most of the time over the Mediterranean Sea (Fig. 2c), and then they penetrate inland over the densely populated Gaza Strip and progress over the desert area for several hours. The backward trajectories presented in Fig. 2 correspond to the starts of the samplings before and during the sea breeze, i.e., 13:00 and 14:30 UTC, respectively. The model also shows that the air masses and therefore the transported aerosol particles at altitudes of 10 and $500 \mathrm{~m}$ are exposed to 60 to $80 \% \mathrm{RH}$ levels several hours before sampling (see bottom panels in Fig. 2). The model also points out some increase in $\mathrm{RH}$ (from 32 to $36 \%$ ) at $10 \mathrm{~m}$ above ground level (a.g.l.) when the sea breeze starts. However, the RH values provided by HYSPLIT are somewhat different from the corresponding values measured by the local meteorological station (indicating increases from 26 to $43 \%$ ); nevertheless, the increasing tendency is consistent.

\section{Instrumentation}

\subsection{Remote sensing setup}

\subsubsection{Sun/sky photometer}

The sun/sky photometric measurements at the Sede Boker site are performed as part of the global Aerosol Robotic Network (AERONET) (Holben et al., 1998). The measurements are conducted with a photometer manufactured by CIMEL Electronique, Paris, France. The automatic direct sun photometric measurements are normally conducted every $15 \mathrm{~min}$ and provide spectral aerosol optical thickness at 340, 380, $440,500,675,870$, and $1020 \mathrm{~nm}$ nominal wavelengths. The $940 \mathrm{~nm}$ channel is used to retrieve the atmospheric water vapor content. The angular distribution of sky radiance is measured at $440,670,870$, and $1020 \mathrm{~nm}$. The measured spectral sun and sky radiances are used for retrieval of aerosol optical 


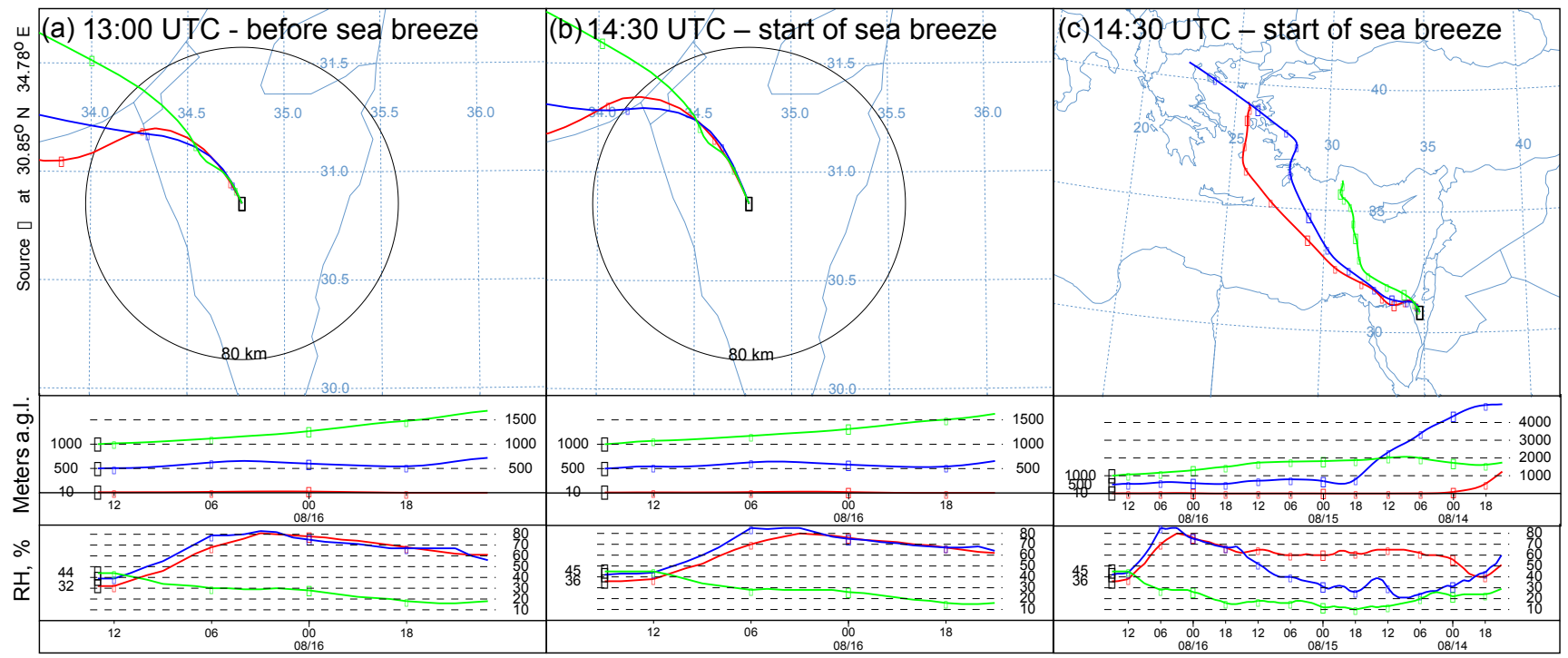

Figure 2. (a, b) 24 h and (c) 3-day backward trajectories ending at 13:00 and 14:30 UTC for altitudes above ground level (a.g.1.) of 10 m (in red), $500 \mathrm{~m}$ (in blue), and $1000 \mathrm{~m}$ (in green) at the Sede Boker site; the corresponding relative humidity along the trajectories is also presented.

parameters at four wavelengths by the AERONET inversion code (Dubovik and King, 2000; Dubovik et al., 2006) that employs models of homogeneous spheres and randomly oriented spheroids. It should be mentioned that the aerosol optical thickness (AOT) during the analyzed period is not always high enough to fulfill requirements of the retrieval accuracy (Dubovik et al., 2000, 2002). In particular, accuracy of the complex refractive index can be limited and variability can be important. Therefore, the parameters designed to control the quality of the retrievals were additionally analyzed and only stable retrievals were used. The spectral aerosol optical thickness measurements are also used for calculating the Angström exponent $(\AA)$ that is an indicator of aerosol size. For instance, between the wavelength of 440 and $870 \mathrm{~nm}, \AA$ is calculated as

$\AA=-\frac{\ln \left(\frac{\tau_{870}}{\tau_{440}}\right)}{\ln \left(\frac{\lambda_{870}}{\lambda_{440}}\right)}$,

where $\tau$ is the AOT and $\lambda$ is the wavelength. An Angström exponent below 0.5 generally indicates an important contribution of coarse mode aerosols, the range between 0.5 and 1.0 corresponds to a bimodal size distribution, and a value above 1.0 indicates a dominant fine-mode aerosol (Eck et al., 1999, 2010).

\subsubsection{Thermal infrared radiometer}

The multichannel thermal infrared (TIR) radiometer is designed to measure thermal radiation emitted by the atmosphere and surface system. The instrument has been de- veloped in collaboration between the Laboratory of Atmospheric Optics (LOA) of University of Lille (Legrand et al., 2000; Brogniez et al., 2003) and the manufacturer CIMEL Electronique. This is the same manufacturer as that of the AERONET photometers, and therefore both instruments have convenient similarities in protocol of functionality that facilitates operations in the field. The TIR radiometer provides radiances and brightness temperatures of a target viewed with a $10^{\circ}$ full field of view. The instrument employed at the Sede Boker site was operating at three $1 \mu \mathrm{m}$ narrowband spectral channels, centered at 8.6, 10.8, and $12.0 \mu \mathrm{m}$, and at an extra broadband channel covering the spectrum from 8 to $14 \mu \mathrm{m}$. The instrument operates in a skyscanning mode and in this study the analyzed values are the sky brightness temperatures from a vertical upward-looking position. The radiometer is equipped with a humidity sensor in order to shut down automatically in case of precipitation or dew to prevent water deposition on the detector. In addition, the system can shut down the instrument when relative humidity is about $80 \%$, which limits the number of observations, mainly during nighttime. The instrument was set up at the site by LOA for a 6-month experimental period and with the purpose of complementary and intensive observations.

\subsubsection{Lidar}

The ground-based lidar observations at the Sede Boker site are conducted as part of the NASA Micro-Pulse Lidar Network (MPLNET) (Welton et al., 2001), wherein sites are generally co-located with the AERONET sites. The MPLNET is a federated network of micropulse lidar systems (Spinhirne et al., 1995, 2002) that uses standardized calibrations, oper- 
ational protocols and processing. The network is supported by the NASA Earth Observing System program (Wielicki et al., 1995). Data products at three levels of processing provide real-time normalized relative backscatter, aerosol and cloud heights, and optical property retrievals (Campbell et al., 2002; Welton and Campbell, 2002), http://kimura.gsfc. nasa.gov/data. In our study, we employ only the vertical distribution of lidar backscatter signal at $532 \mathrm{~nm}$ for the purpose of illustration of vertical and temporal variability in the aerosol loading.

\subsubsection{Broadband solar flux}

The Solar Radiation Network (SolRad-Net, http://solrad-net. gsfc.nasa.gov) is associated with the AERONET network of federated ground-based sensors that provides high-frequency measurements of solar flux in quasi-real time. Similar to MPLNET, the sites are co-located with AERONET, and standardized calibrations and operational protocols are applied to the measurements. In general, SolRad-Net provides measurements from several flux instruments including filtered and unfiltered pyranometers, photosynthetically active radiation (PAR) and ultraviolet (UV-A and UV-B). In this study, we use the broadband shortwave solar spectrum $(0.3-2.8 \mu \mathrm{m})$ irradiance, measured by a Kipp and Zonen CM-21 pyranometer. The data correspond to quality level 1.5, which means that the data have been cloud-screened and cleared of any operational problems. The instantaneous irradiance analyzed at the Sede Boker site is recorded at $10 \mathrm{~min}$ intervals.

\subsection{Backward trajectories}

The air mass backward trajectories are obtained using the 3D HYSPLIT (HYbrid Single-Particle Lagrangian Integrated Trajectory) model of the US National Oceanic and Atmospheric Administration (NOAA) (Draxler and Hess, 1998). The runs for backward trajectories are performed using the global data assimilation system. This is performed for altitudes above ground level of 1000,500 , and $10 \mathrm{~m}$, as an indicator of origin of air masses near the surface. The relative humidity at the corresponding altitudes and time is also available along the backward trajectories from HYSPLIT.

\subsection{In situ measurement and sampling}

\subsubsection{Integrating nephelometer}

Near ground, the light scattering extinction coefficient at $545 \mathrm{~nm}$ is measured with a 2 min temporal resolution using a single-wavelength integrating nephelometer (M903, Radiance Research, Seattle, WA, USA). The inlet is located outdoors on a roof at $\sim 10 \mathrm{~m}$ above ground and faces downward. The instrument itself is situated indoors and air is supplied through plastic tubing of up to $3 \mathrm{~m}$ length, with a $2.2 \mathrm{~cm}$ internal diameter. The instrument was set up in November 1999 and has been regularly calibrated in the field until Novem- ber 2003. The variability in the calibration coefficients during this time was within $6 \%$. A different strategy was applied afterwards when a series of reference tests with particle-free air and $\mathrm{CO}_{2}$ as a calibration gas were periodically conducted; the procedure enables the variability in the calibration coefficients to be traced and correction to the measured values to be applied. In this study we do not intend to evaluate the long-term temporal trend; the observations are used only for a confirmation of the response of the near-ground aerosol optical properties to the sea breeze arrival. Thus, the abovementioned corrections are not needed in the analysis of diurnal variability in the scattering coefficient on a specific day. Relative humidity $(\mathrm{RH})$ in the scattering volume of the instrument is also of importance since a nonlinear increase in the scattering coefficient is possible when $\mathrm{RH}$ is above $80 \%$ (Andreae et al., 2002). Thus, early morning and late evening data, when the RH is elevated, should be interpreted as a high limit. Nevertheless, the behavior of the measured scattering coefficient observed in this study is generally consistent with other independent measurements at the site.

\subsubsection{Aerosol sampling}

Aerosol samples were collected on the rooftop terrace of a three-story building, adjacent to the nephelometer inlet. Ambient particles were sampled before and during sea breeze flow using a three-stage cascade impactor $\left(\mathrm{PM}_{10}\right.$, Dekati Ltd.) at a flow rate of $10 \mathrm{~L} \mathrm{~min}^{-1}$. The nominal cut-off sizes (i.e., aerodynamic diameters at $50 \%$ of collection efficiency for a particle density of $0.93 \mathrm{~g} \mathrm{~cm}^{-3}$; Marjamaki et al., 2000) of the impactor stages were $10,2.5$, and $1 \mu \mathrm{m}$, respectively. Note that because the size-segregated sampling by a cascade impactor is based on an aerodynamic cut-off diameter at $50 \%$ of collection efficiency and depends on the particle density, particles smaller or bigger than the cut-off diameter can also be present on the collection stage. Sampling durations ranged from $15 \mathrm{~min}$ to an hour, depending on the ambient aerosol load. Particles were deposited simultaneously onto 200-mesh copper TEM grids with carbon type-B supporting films (Ted Pellar, Inc.) and Nuclepore ${ }^{\mathrm{TM}}$ polycarbonate membranes for SEM/EDX particle microanalysis. Additionally, particles were collected on glass slides for Raman microspectroscopy. Samples were sealed in aluminum foil bags and stored at $4{ }^{\circ} \mathrm{C}$ pending analysis. Among several samples collected during the campaign, samples from 16 August 2012 were selected as representative of the described phenomenon and are presented here in detail. The sampling time and duration were most successful for representing conditions the before and during the sea breeze; the phenomenon itself was also well pronounced and measured by all other instruments. The sampling conditions for this day are reported in Table 1 and discussed in detail in Sect. 2. 


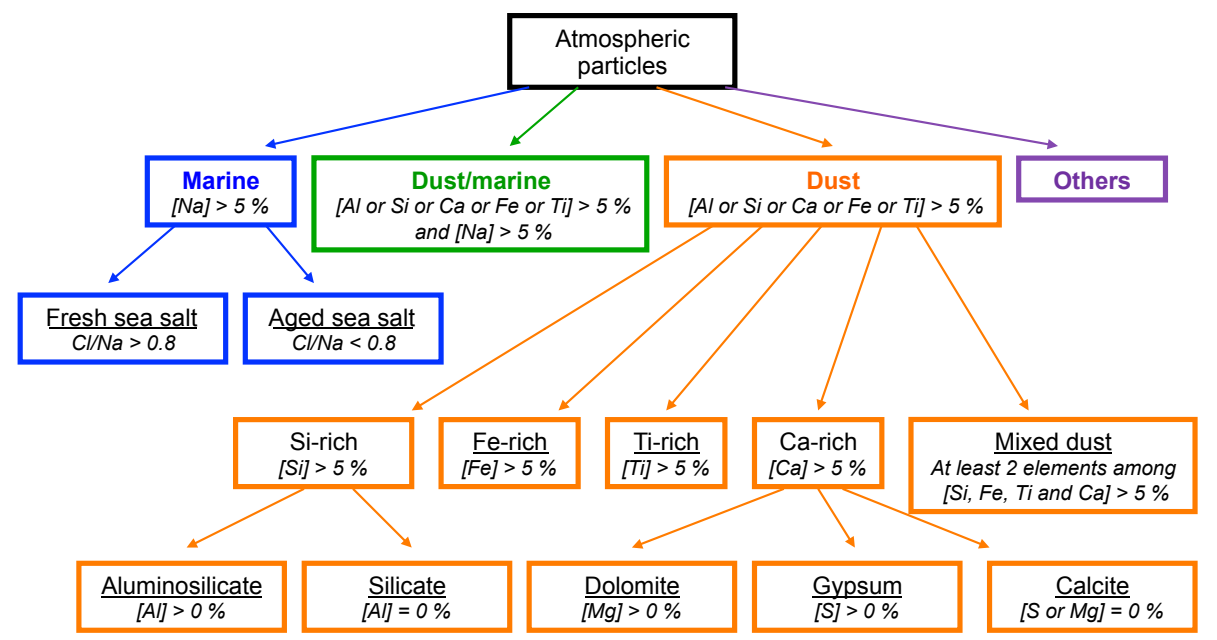

Figure 3. Particle classification (colored text) and identification (underlined text) based on normalized atomic percentages for elements with $Z>10$.

Table 1. Sampling conditions: values of relative humidity, air temperature, and wind speed and direction are mean values during the sampling time.

\begin{tabular}{|c|c|c|}
\hline $\begin{array}{l}\text { Date: } \\
16 \text { Aug } 2012\end{array}$ & $\begin{array}{l}\text { Sample } 1(\mathrm{~S} 1) \text { : } \\
\text { before sea } \\
\text { breeze }\end{array}$ & $\begin{array}{l}\text { Sample } 2 \text { (S2): } \\
\text { during sea } \\
\text { breeze }\end{array}$ \\
\hline Start time & 13:00 UTC & 14:30 UTC \\
\hline Duration & $60 \mathrm{~min}$ & $15 \mathrm{~min}$ \\
\hline $\mathrm{RH}(\%)$ & 28.5 & 52.0 \\
\hline Air temperature $\left({ }^{\circ} \mathrm{C}\right)$ & 32 & 30 \\
\hline Wind speed $\left(\mathrm{m} \mathrm{s}^{-1}\right)$ & 4.0 & 7.3 \\
\hline Wind direction $\left(^{\circ}\right)$ & $306(\mathrm{NW})$ & $308(\mathrm{NW})$ \\
\hline
\end{tabular}

\subsection{Chemical characterization at the particle scale}

Offline laboratory chemical imaging of the sampled atmospheric particles was carried out using SEM/EDX and Raman microspectroscopy.

\subsubsection{Scanning electron microscopy with energy-dispersive $\mathrm{X}$-ray spectrometry (SEM/EDX)}

Single-particle analysis by SEM/EDX was performed with a FEI Quanta 200 SEM equipped with an ultrathin-window energy-dispersive X-ray detector enabling the analysis of elements with atomic number higher than boron $(Z \geq 5)$. However, for samples collected on polycarbonate membranes, elements lighter than sodium $(Z<11)$ were not quantified because of high absorption within the samples due to carbon coating and substrate material. Automated particle analysis was run using the commercially available Link ISIS Series 300 Microanalysis system (Oxford Instruments ${ }^{\circledR}$ ). The procedure of automatic particle recognition and analysis is de- scribed elsewhere (Choël et al., 2005). X-ray spectra were acquired with a counting time of $30 \mathrm{~s}$, with an accelerating voltage of $20 \mathrm{kV}$ and a probe current adjusted to $200 \mathrm{pA}$. The identification of individual particles is based on their elemental composition obtained from SEM/EDX data; the procedure and the criteria were described in a previous study (Deboudt et al., 2010). Elemental composition of particles is reported in this work as normalized atomic percent. Figure 3 shows the particle-classification chart used in the case of Negev particles. To elucidate the mixing state of particles, the analyzed particles were sorted into four different groups: Dust, Marine, Mixed Dust/Marine, and Other. Particles sorted into the "Dust" particle type were composed of silicate (Si-rich), aluminosilicate (Al- and Si-rich), calcite (Ca-rich), dolomite (Ca- and $\mathrm{Mg}$-rich), gypsum (Ca- and Srich), and Ti-rich particles. The "Marine" particle type comprises fresh (Na- and $\mathrm{Cl}$-rich) and aged (Cl-depleted) sea salts. Particles that contain sea salts internally mixed with crustal elements were assigned to the "Mixed Dust/Marine" particle type. Particles not assigned to the previous particle types were sorted into the "Other" particle type, comprising notably $\mathrm{Mg}-$ - $\mathrm{S}-, \mathrm{K}-$, and $\mathrm{KCl}$-rich particles. Complementary manual examination of particles was performed using a HORIBA S-4700 field emission scanning electron microscope (FE-SEM).

\subsubsection{Raman microspectroscopy}

Raman spectra were recorded for atmospheric particles in the coarse fraction (i.e., $\mathrm{PM}_{2.5-10}$ ). The glass plates with impacted particles were directly mounted on the microscope stage of a LabRAM HR confocal Raman microscope (Horiba Scientific) equipped with an Olympus $100 \times$ objective with a numerical aperture of 0.90 . Raman scattering was excited at $632.8 \mathrm{~nm}$ using a $\mathrm{He}-\mathrm{Ne}$ laser. The laser spot size focused on 
the sample was $0.9 \mu \mathrm{m}$. To avoid laser damage to the sample, a neutral density filter with an optical density value of 0.6 was used. Raman measurements were carried out at ambient conditions $(\sim 60 \% \mathrm{RH}$ and $295 \mathrm{~K})$. Raman spectral mapping provides the spatial distribution of the various molecular species within heterogeneous samples. The acquisition of computer-controlled Raman maps consisted in recording spectra in a point-by-point XY scanning mode with a $1 \mu \mathrm{m}$ step and $10 \mathrm{~s}$ of integration time. According to the diffraction grating of 300 grooves per millimeter used in this work, Raman spectra were acquired in the range $170-2440 \mathrm{~cm}^{-1}$ with a spectral resolution of about $4 \mathrm{~cm}^{-1}$. The data processing of Raman maps was the following. The baseline was estimated individually for each spectrum using asymmetric least squares (ALS) proposed by Eilers (2003) and Eilers and Boelens (2005). The order of differences $d$ was set to 3 (classical value), whereas the trade-off parameter $(\lambda)$ and the asymmetry parameter $(p)$ were optimized for each map by visual inspection of the estimated baseline and the spectra after correction. Best results were obtained for a $p$ value of 0.01 and $10^{8}$ for $\lambda$. The color map was obtained from the baseline corrected data using the net Raman intensity signal at a specific wavelength over all point spectra. The differences in the center positions of characteristic Raman bands were selected to minimize overlap of the characteristic Raman peaks of the several compounds present in the aerosol samples. For the color map, intensity close to zero corresponds to black and the maximum signal intensity to bright color.

\section{Remote sensing observations}

Similarly to the meteorological parameters described in Sect. 2, recurrent abrupt changes in atmospheric aerosol optical characteristics can be observed nearly every day during the summertime, which is true not only for 2012 but for all preceding and subsequent years. An example of several consecutive days of atmospheric remote sensing measurements during August 2012 is presented in Fig. 4. The figure shows daily variability in AOT at $440 \mathrm{~nm}$, Ångström exponent between 870 and $440 \mathrm{~nm}$ and total column water vapor derived from AERONET photometric measurements, and sky brightness temperature from the narrowband channels of the thermal infrared radiometer. In conjunction with the meteorological parameters, an analysis of the data in Fig. 4 suggests that the abrupt changes in the remote sensing measurements coincide with sharp changes in the air mass as the sea breeze arrives. Note that in this example of 9 days, the sea breeze occurs and influences the optical measurements on 8 days. The AOT increases and the Ångström exponent decreases significantly when the sea breeze arrives (Fig. 4a). A decrease in the Ångström exponent indicates an increased contribution of large aerosol particles. Attention can also be drawn to the recurrent increase in the sky brightness temperature and change in its spectral dependence, as measured by the thermal in- frared radiometer from the ground. The measurements therefore show that the spectral radiative properties in the thermal infrared change significantly during the penetration of the sea breeze (Fig. 4c), similar to the solar spectra (Fig. 4a). While the variability in AOT and the Angström exponent in the solar spectrum is due to the change in aerosol particles properties only, several processes can cause variability in the sky thermal infrared emission. Atmospheric water vapor can absorb solar and thermal radiation as well as emit thermal radiation; water droplets and aerosol particles can absorb and scatter solar and thermal radiation as well as emit thermal radiation. Thus, in general, the sky brightness temperature can increase either due to higher atmospheric water vapor content or due to appearance of large mineral dust particles or water droplets. Aerosol particles and droplets have primary radiative effects in the $10.8 \mu \mathrm{m}$ channel of the radiometer, at the center of the $10 \mu \mathrm{m}$ window, where the atmospheric gaseous transmittance is higher (and the sky brightness temperature is minimum). Emission of the thermal radiation by water vapor is stronger in the channels centered at 8.6 and $12 \mu \mathrm{m}$, located in the outer sides of the window. Now, the spectral dependence (represented by the ratio of brightness temperatures) between the channel at $10.8 \mu \mathrm{m}$ and the channel at $8.6 \mu \mathrm{m}$, which is more affected by water vapor, indicates a stronger increase in the sky thermal emission at $10.8 \mu \mathrm{m}$ relative to $8.6 \mu \mathrm{m}$ during periods with sea breeze (Fig. 4c). Therefore, an increase in the brightness temperature ratio (10.8 to $8.6 \mu \mathrm{m}$ ) suggests the appearance of not only water in the gas phase but also of large particles or water droplets. Note also that the ratio of brightness temperatures in Fig. 4c is approaching the value of one at the time of sea breeze arrival, that is, the spectral dependence of brightness temperature is approaching to neutral, which is a typical characteristic of clouds. The brightness temperature could also increase due to the arrival of a warmer air mass. However, as the meteorological data show, the arrival of the sea breeze is, however, associated with cooler air, while the water vapor content and amount of aerosol increase (Fig. 4a, b).

A more quantitative interpretation of the TIR signal requires accurate radiative transfer computations that also require information about vertical profiles of the aerosol extinction, concentrations of gas phase species and temperature, which are not available for the site of interest. The same information is needed for evaluation of the aerosol radiative forcing in TIR. However, the presented TIR radiometer measurements and the diurnal behavior of the sky brightness temperature are already informative. The measured sky brightness temperature shows that increase in the amount of water vapor and large size aerosol is likely to increase the TIR radiative warming at the surface that generally counteract the aerosol cooling effect in the solar spectrum. The TIR measurements are also in line with the photometric observations in the solar spectrum by AERONET. That is, an abrupt increase in the AOT is observed when the sea breeze arrives. It is also interesting to note that the increase in the AOT is 


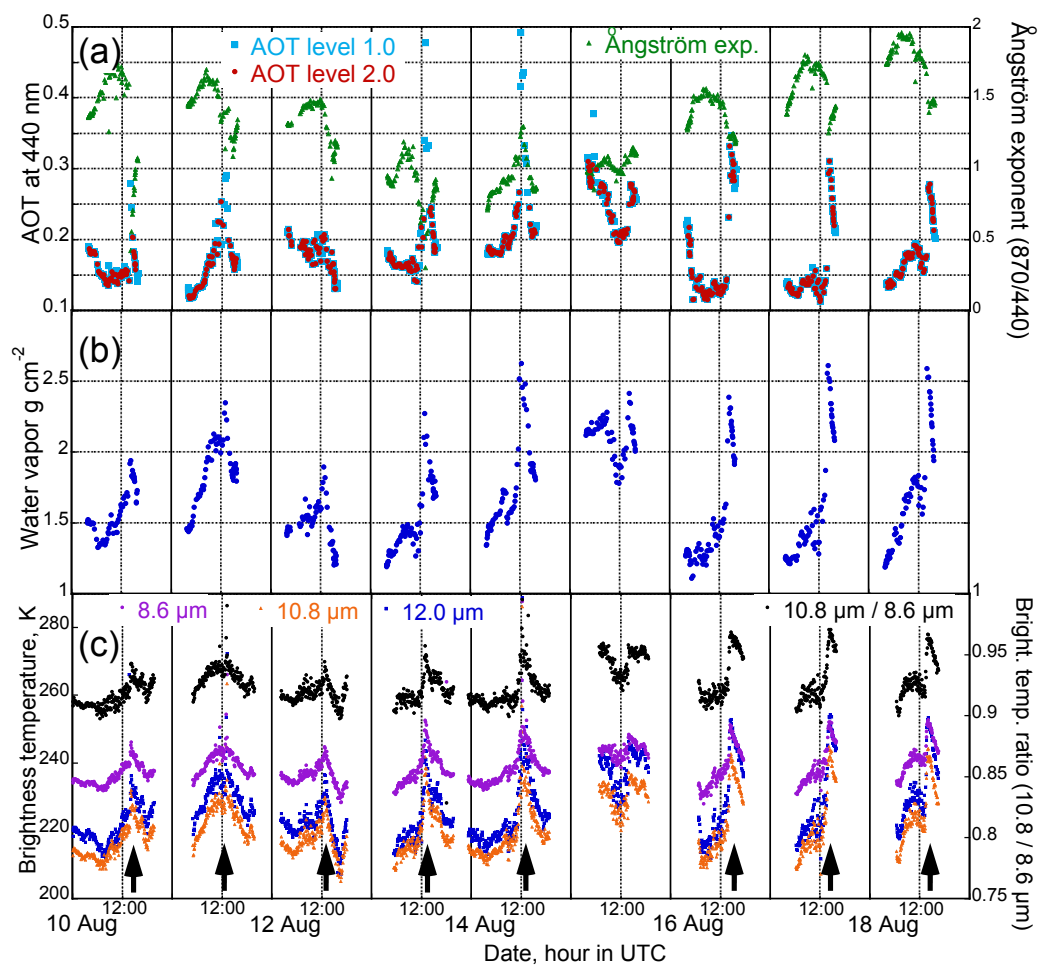

Figure 4. Time series of (a) AERONET observations of AOT at $440 \mathrm{~nm}$ (before application of the cloud screening algorithm, level 1.0; after the cloud screening, level 2.0) and Ångström exponent between 870 and $440 \mathrm{~nm}$, (b) AERONET-derived total column water vapor and (c) sky brightness temperature as measured by the thermal infrared radiometer at three spectral channels and ratio of brightness temperatures at 10.8 to $8.6 \mu \mathrm{m}$. Arrows indicate the signal peaks corresponding to the sea breeze arrival, which occurred on 8 of the 9 days presented.

often screened as a cloud because normally the aerosol properties do not change as fast in time and the screening algorithm could fail. An example of the unscreened AERONET data (level 1.0) and of these data after the cloud-screening algorithm has been applied (level 2.0) is presented in Fig. 4a.

In order to understand and describe in detail the phenomenon, we focus on a specific, but typical, day (16 August) when a sampling of aerosols was conducted and analyzed in conjunction with remote sensing observations before and during the sea breeze. Figure 5 shows that at around 14:00 UTC (17:00 local time), the AOT, total column water vapor, scattering coefficient at the ground level, and sky brightness temperature have a sharp increase, while the Ångström exponent decreases. The lidar backscatter signal also increases in altitudes up to $1.8 \mathrm{~km}$. The phenomenon reaches a maximum at the sea breeze front and then decays gradually. The photometer acquisition is stopped after 16:00 UTC because of the low sun, but the lidar, the thermal infrared radiometer, and the nephelometer measurement remain available. From the temporal variability in the signal of these three instruments one can estimate that the effect of the sea breeze lasted until about 17:00 UTC, i.e., for about $3 \mathrm{~h}$. It can also be noted that some gradual increase in water vapor and brightness temperature starts already about $2 \mathrm{~h}$ before the front of the sea breeze arrives. The increase in the water vapor amount towards noontime is a usual process related to increasing temperature and evapotranspiration that influences the thermal infrared signal. It is noteworthy that the increase in water vapor is also correlated with a gradual decrease in the Angström exponent, i.e., increase in the aerosol size, which can also be responsible for a gradual increase in the sky brightness temperature before the abrupt change occurs. In addition to the column-integrated remote sensing measurements, the scattering coefficient, which is measured by nephelometer near the ground, shows that the abrupt change in aerosol characteristics occurs also at the surface level (Fig. 5c). This fact supports representativeness of the particle sampling described in Sect. 3.3.2. The diurnal variability in scattering coefficient is also correlated with the ambient RH (Fig. 1d). This is despite the fact that the nephelometer generally dries the aerosols inside the measurement volume and the RH inside the instrument is much more stable than the ambient RH. The variability in the scattering coefficient can be due to change in either aerosol concentration or microphysical characteristics, like size, but it is difficult to draw a conclusion based on only a single wavelength measurement. In summary, all the abovementioned observations of the aerosol optical properties in the solar spectrum and radiation in the thermal infrared wavelength region manifest a coherent abrupt response associated with the sea breeze ar- 


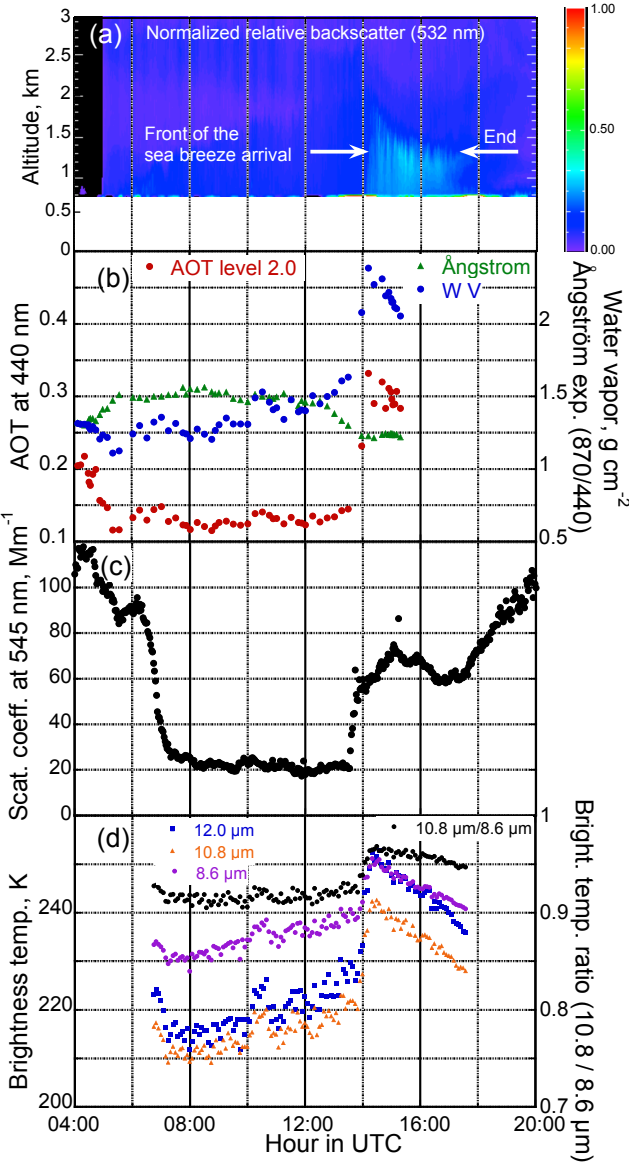

Figure 5. Diurnal variability on 16 August 2012 of (a) vertical distribution of lidar backscatter signal at $532 \mathrm{~nm}$ (it starts from about $700 \mathrm{~m}$ since observations are generally omitted in the first lower hundreds meters); (b) AOT at $440 \mathrm{~nm}$ (level 2.0 - after the cloud screening and quality assurance), Ångström exponent between 870 and $440 \mathrm{~nm}$, and total column water vapor; (c) scattering coefficient at $545 \mathrm{~nm}$; and (d) sky brightness temperature measured by the thermal infrared radiometer in channels centered at 8.6, 10.8, and $12.0 \mu \mathrm{m}$ and ratio of brightness temperatures at 10.8 to $8.6 \mu \mathrm{m}$.

rival. An abrupt response in the aerosol optical characteristics can be due to not only a higher aerosol concentration but also to a change in the aerosol microphysical characteristics and influence of the increasing atmospheric water content.

In order to examine whether a change in the aerosol microphysical parameters is taking place during the sea breeze, we use the remote sensing observations of the aerosol volume size distribution and the complex refractive index as retrieved by the AERONET algorithm. On 16 August, the average volume size distribution during the sea breeze is significantly different from the size distribution before the sea breeze. It shows an increase in the volume concentration and a size shift towards large sizes (Fig. 6a, b). The aerosol volume concentration is defined as a product of particle number concentration and particle volume. Thus, both the number concentration and the particle size may contribute. Indeed, a stronger wind speed during the sea breeze can lift aerosols along the path of transport and increase the aerosol number concentration. However, as Fig. $6 \mathrm{~b}$ shows, the particle radii are also increasing. The volume size distribution in Fig. $6 \mathrm{~b}$ is normalized to the total volume concentration in order to enable a better comparison of the distribution shapes, which emphasizes the shift of the radii. It can be noted that the average water vapor concentration is also increasing from 1.4 to $2.2 \mathrm{~g} \mathrm{~cm}^{-2}$. Figure $6 \mathrm{c}$ and $\mathrm{d}$ present average size distributions obtained for 51 days when the AERONET inversions are available and the sea breeze is clearly observed in the meteorological data during summer 2012. Note that the sea breeze days occur almost $60 \%$ of the time in this case. Variability in the water vapor concentration is generally important on such days. The averages are calculated for three different ranges of the water vapor concentration. Figure $6 \mathrm{c}$ and $\mathrm{d}$ show that a shift in size distribution, similar to on 16 August, occurs also in the 3 months of data of summer 2012. It also appears that the particles of the fine mode are affected more strongly than those of the coarse mode. We thus do a similar analysis for March and April of the same year (24 days are analyzed) when the aerosol regime in the Negev Desert is very different and is governed mainly by African dust transport. The average water vapor during this dry air mass transport does not exceed $2 \mathrm{~g} \mathrm{~cm}^{-2}$ and no shift is observed either in the fine or in the coarse modes of the size distributions (Fig. 6e, f). Also, the maximum radius of the coarse mode during the spring is about $2 \mu \mathrm{m}$ in contrast to $2.5-3 \mu \mathrm{m}$ during the summer.

The real and imaginary parts of the complex refractive index and their spectral dependences are related to the aerosol particles' chemical composition. As the real part of the refractive index of liquid water in the visible spectrum is 1.33 , it is expected that the real part of the refractive index of water-containing aerosols will decrease and approach the value of water. Figure 7 shows that this is the case for observations during the sea breeze (Fig. 7a) and for sea breeze days associated with increased water vapor concentration (Fig. 7c). The mean real refractive index is also somewhat lower at increasing water vapor concentration in the dust case of spring 2012 (Fig. 7e); however, there is no significant change in the corresponding size distributions (Fig. 6f). The imaginary part of the complex refractive index of pure water in the visible spectrum is practically zero; the marine aerosol, for example, is known to be non-absorbing (Dubovik et al., 2002). It is therefore expected that the imaginary part will also decrease with increasing water content in the aerosol. The observations show, however, that the imaginary part for all analyzed cases slightly increases (Fig. 7b, d, f). Indeed, since the sea breeze air masses can bring pollution aerosols, it is suggested that the reason for the increase in the imaginary part may be the presence of absorbing carbonaceous particles. The imaginary part also increases for the dust case, where we do not expect a carbonaceous aerosol contribution. At the same time, the standard errors are overlapping the 

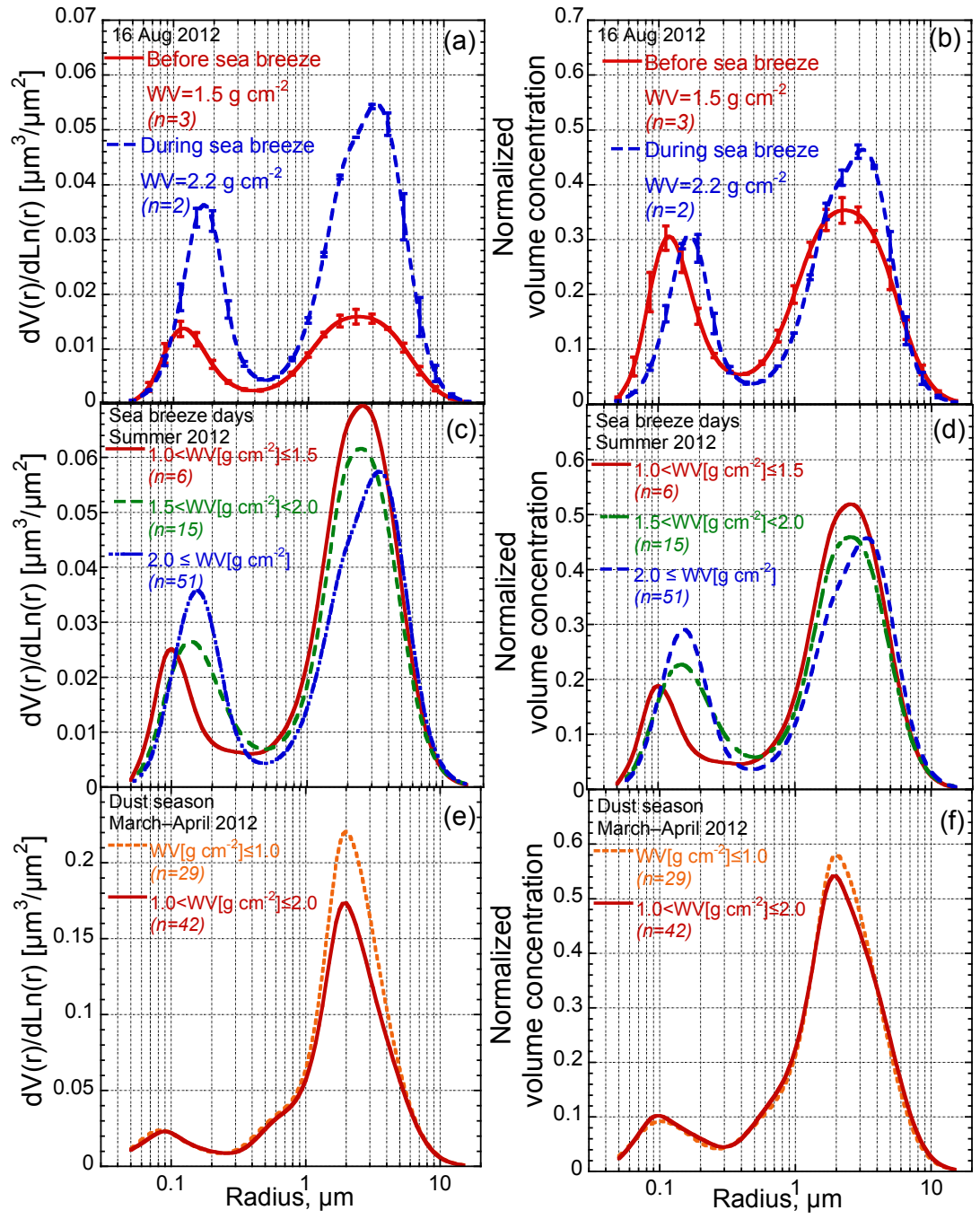

Figure 6. The left column shows aerosol volume size distributions and the right column shows these size distributions normalized to total volumes. The data are sorted by water vapor (WV) concentration. Panels (a, b) are for 16 August 2012; (c, d) are the averaged size distributions for the sea breeze days of summer months (JJA), 2012; and (e, f) are for the dust period (March-April) of 2012. Error bars in (a, b) correspond to the standard error, and $n$ is the number of data points used to compute the averages; the error bars in (c-f) overlap, and for clarity of the figure, are not shown.

means indicating that the differences for the imaginary part are not significant. It has to be mentioned that the sensitivity of the AERONET measurements to the complex refractive index is rather limited to bear a solid conclusion; sensitivity to the changes in aerosol size distribution, however, is quite high (Dubovik et al., 2000) since the sun photometer primarily measures the forward-scattered radiation, which strongly depends on the particle size.

The aerosol single-scattering albedo (SSA), which is defined as the ratio of the scattering coefficient to the total extinction coefficient and represents the scattering effectiveness in total extinction, is one of the key parameters determining the aerosol radiative effect. The change in the spectral SSA (at wavelengths $440 / 670 / 870 / 1020 \mathrm{~nm}$ ) on $16 \mathrm{Au}$ - gust is from $0.968 / 0.962 / 0.961 / 0.963$ before the sea breeze to $0.955 / 0.953 / 0.955 / 0.957$ during the sea breeze, respectively. As the imaginary part of refractive index is higher, the SSA becomes generally lower, indicating a stronger contribution of aerosol absorption. However, the SSA also depends on the aerosol size, or more exactly on the size parameter, which is defined as the ratio of the particle size to the wavelength of light. Because both the size distribution and the complex refractive index change during the sea breeze, it is interesting to evaluate their specific contribution to the changes in the SSA. To address this question, we calculate the SSA assuming that only the size distribution is changing, while the refractive index is the same and vice versa. The difference in the SSA of the before-sea-breeze aerosol model minus the SSA of 

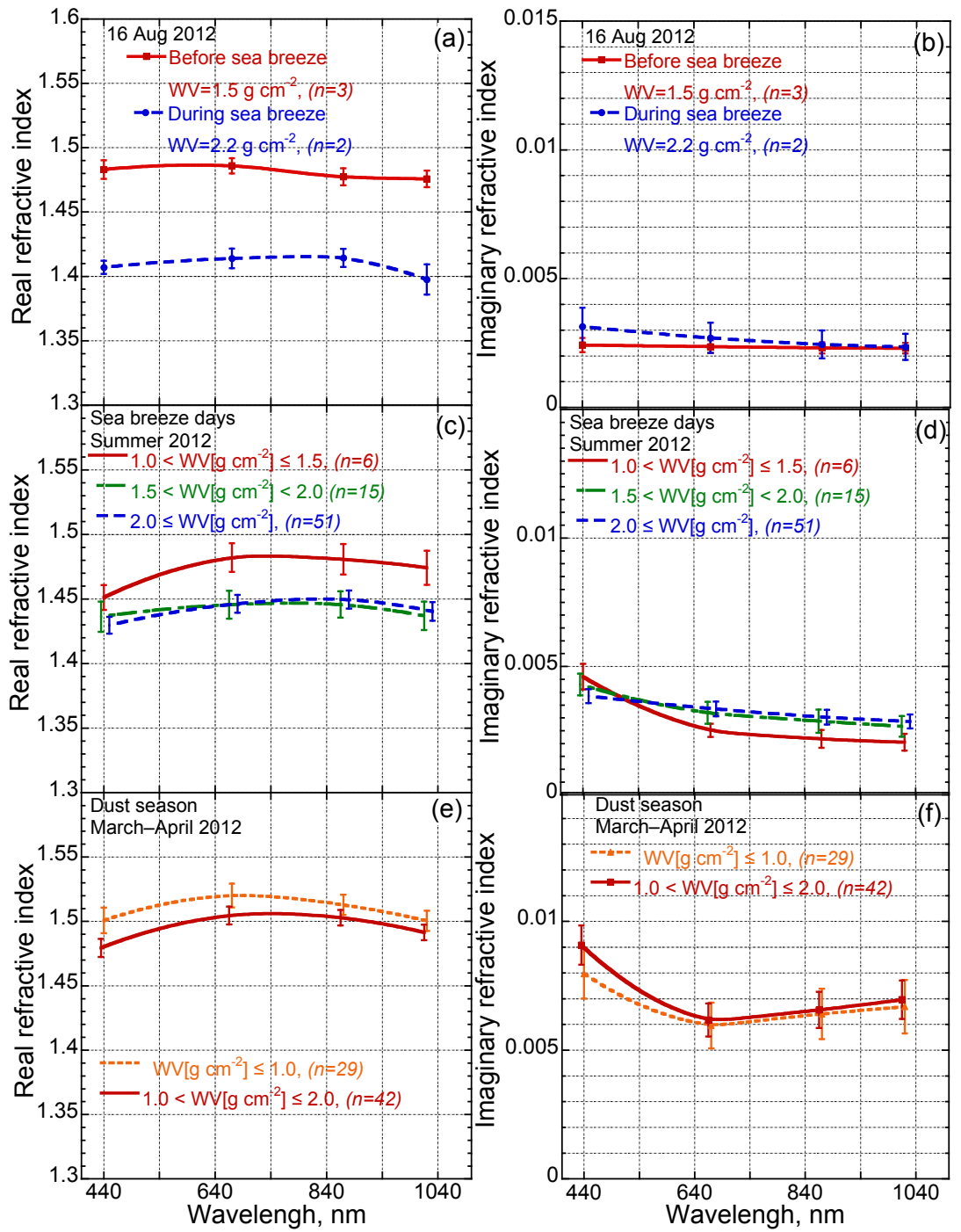

Figure 7. The left column shows the real part and the right column shows the imaginary part of averaged values of the complex refractive index as retrieved by AERONET. The data are sorted by water vapor (WV) concentration. Panels (a, b) are for 16 August 2012; (c, d) are for sea breeze days of summer months (JJA), 2012; and (e, f) are for the dust period (March-April) of 2012. Error bars correspond to the standard errors, $n$ is the number of data points used to compute the averages.

the modified aerosol model is $-0.002 /-0.001 / 0.001 / 0.003$ for the size change and $0.015 / 0.009 / 0.003 / 0.003$ for the refractive index change. The calculated differences show that the scattering effectiveness increases at the shorter and decreases at the longer wavelengths due to the size change, and decreases at all the wavelengths due to the compositional change. The calculations show that there is a partial compensation of the decrease in SSA at the shorter wavelengths because of the size shift.

\section{Individual particle analysis}

\subsection{Elemental analysis of particles by SEM/EDX}

Additional insights into the microphysical properties and mixing state of ambient particles are provided by computercontrolled SEM/EDX (CCSEM/EDX) analyses of aerosol sampled before and during the sea breeze on $16 \mathrm{Au}$ gust 2012. A total of 2077 particles were analyzed. Each particle was assigned to one of the particle types, defined in Sect. 3.4.1: Marine, Dust, Mixed Dust/Marine, and Other. The pie charts in Fig. 8 present particle-type fractions in size range of $\mathrm{PM}_{1-2.5}$ and $\mathrm{PM}_{2.5-10}$ collected before and during the sea breeze event. Considering all analyzed particles for this sampling day $(n=2077)$, the most 


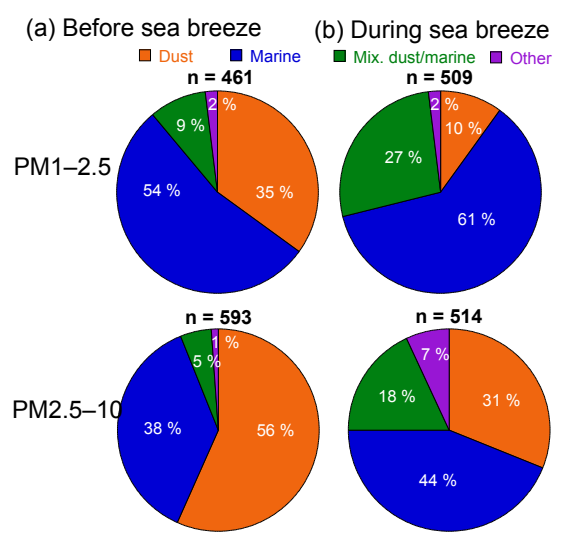

Figure 8. Percentage of particles number for each aerosol type obtained from CCSEM/EDX analysis of particles collected before the sea breeze (a) and during the sea breeze (b). $\mathrm{PM}_{1-2.5}$ and $\mathrm{PM}_{2.5-10}$ denote the particle size intervals that correspond to the aerodynamic cut-off diameters ( 1 and $2.5 \mu \mathrm{m}$, respectively) of the cascade impactor stages. Particles are sorted into the following four main types: Marine, Dust, Mixed Dust/Marine, and Other. The total number $(n)$ of the analyzed particles is also indicated in each panel of the figure.

abundant elements (excluding $\mathrm{C}, \mathrm{N}$, and $\mathrm{O}$ ) were identified and the normalized average composition was calculated as $\mathrm{Na}_{1} \mathrm{Mg}_{0.08} \mathrm{Al}_{0.11} \mathrm{Si}_{0.31} \mathrm{~S}_{0.07} \mathrm{Cl}_{0.04} \mathrm{~K}_{0.03} \mathrm{Ca}_{0.28} \mathrm{Fe}_{0.04}$. Overall, the "Marine" particle type represented $48.4 \%$ of all analyzed particles. Its average composition is $\mathrm{Na}_{1} \mathrm{Mg}_{0.04} \mathrm{~S}_{0.03} \mathrm{Cl}_{0.04}$, indicative of nearly complete processing of sea-salt particles by $\mathrm{HNO}_{3}$ and formation of $\mathrm{NaNO}_{3}$ as a reaction product. The "Dust" particle type accounted for $34.3 \%$ of all analyzed particles. Its average composition is $\mathrm{Mg}_{0.05} \mathrm{Al}_{0.36} \mathrm{Si}_{1} \mathrm{Ca}_{0.82} \mathrm{Fe}_{0.11}$, suggestive of aluminosilicates and calcium carbonates. The "Mixed Dust/Marine" type contributed $14.6 \%$ of all analyzed particles with an average composition of $\mathrm{Na}_{1} \mathrm{Mg}_{0.11} \mathrm{Al}_{0.08} \mathrm{Si}_{0.21} \mathrm{~S}_{0.1} \mathrm{Cl}_{0.04} \mathrm{~K}_{0.05} \mathrm{Ca}_{0.36} \mathrm{Fe}_{0.04}$, which is typical of internal mixtures of dust and processed sea salts. With an average composition of $\mathrm{Mg}_{0.65} \mathrm{~S}_{0.65} \mathrm{Cl}_{0.3} \mathrm{~K}_{1}$, the "Other" particle group represented $2.7 \%$ of all analyzed particles and comprised $\mathrm{Mg}$-, S-, and K-rich particles.

Before the sea breeze, dust was the predominant particle type in the coarse fraction (56\%) and was the second largest category in the fine fraction (35\%). An increase in both marine and mixed dust/marine particle types was clearly observed during the sea breeze. Therefore, the transport of marine particles during the sea breeze was confirmed by an increase from 38 to $44 \%$ in the coarse fraction and from 54 to $61 \%$ in the fine fraction. Similarly, the internal mixing of dust with marine particles increased from 5 to $18 \%$ in the coarse fraction and from 9 to $27 \%$ in the fine fraction. These results are consistent with those obtained by Sobanska et al. (2003) at the same sampling site on a specific day in the summer period (sampling duration includes be- fore/during/after sea breeze): a high proportion of sea salt (35\% in the coarse size fraction $\mathrm{PM}_{2-10}$ and $12 \%$ in the fine fraction $\left.\mathrm{PM}_{2}\right)$ and mixed sea salt/mineral dust $(\sim 15 \%$ in the fine fraction $\mathrm{PM}_{2}$ ) representative of a marine source contribution. In addition, they reported a high proportion of aluminosilicates $(\sim 30 \%)$ and $\mathrm{CaCO}_{3}(\sim 17 \%)$ in approximately the same proportion in fine and coarse fractions. It is noteworthy that during the sea breeze a new type of particles was detected, accounting for 2 and $7 \%$ of the analyzed particles in the fine and coarse fractions, respectively. These particles sorted into the "Other" particle type were smaller than $1 \mu \mathrm{m}$ in diameter and composed of potassium salts. Submicrometer-sized K-rich and KCl-rich particles can originate from biomass and waste burning emissions (Li et al., 2003), which however are not typical as known aerosol sources in the Negev Desert. However, given that the air masses passed over the densely populated coastal area (see trajectories over Gaza area in Fig. 2), an anthropogenic source of these K-rich particles, e.g., from waste burning fires and cooking, is plausible. Moreover, the K-rich particles in the fine fraction have been already reported for the Sede Boker site previously (Formenti et al., 2001).

\subsection{Number size distribution of particles by SEM/EDX}

Figure 9 shows the particle number size distributions derived from analysis of images acquired by CCSEM/EDX. The presented radius is the one of an equivalent circle area of the 2Dprojected particle on SEM images, which represents the geometric properties. Note also that the maximal nominal cut-off aerodynamic diameter of the analyzed stage of the impactor is $10 \mu \mathrm{m}$. Therefore, it should be realized that the size distributions in Fig. 9 and those retrieved from remote sensing in Fig. 6 are directly incomparable, for example, see discussions in Reid et al. (2003). In addition, it should be realized that the size distributions of the particle types in Fig. 9 are not directly comparable to the percentage of the particle types per size fraction in Fig. 8. This is because the particle type percentages in Fig. 8 are for the size fractions of a cascade impactor, which are defined by aerodynamic cut-off diameters, while Fig. 9 presents the geometric radius derived from equivalent circle area of particles observed by SEM. However, the size distributions per particle type in Fig. 9 and their relative variability can be informative. Figure 9 shows the total number size distributions and the number size distributions for the four aerosol types separately before and during the sea breeze. The total size distribution before the arrival of the sea breeze is mainly defined by dust and marine particles with concentration maxima at radii of about 0.25 and $0.75 \mu \mathrm{m}$, respectively (Fig. 9a). During the sea breeze, the total number size distribution is split into two modes with maxima centered at radii of about 0.4 and $1.75 \mu \mathrm{m}$ (Fig. 9b). This is mainly due to contributions from marine particles. The mean size of coarse marine particles observed during the sea breeze is shifted towards larger sizes, i.e., an increase in ra- 

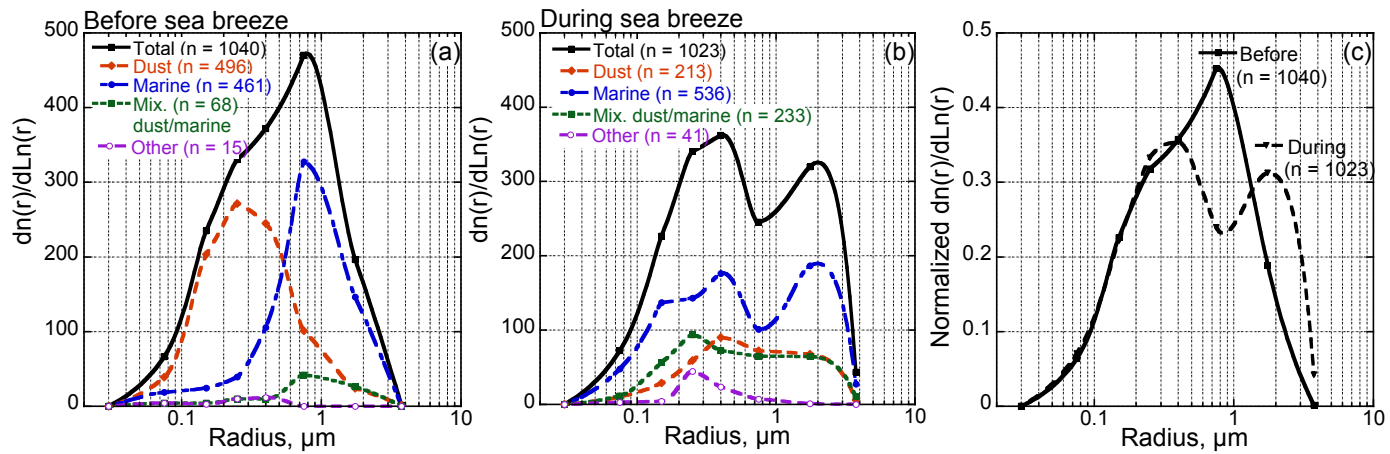

Figure 9. Number size distributions of particles analyzed by CCSEM/EDX - (a) before the sea breeze, (b) during the sea breeze. (c) Size distributions normalized to the total number of particles analyzed for cases before and during the sea breeze.

dius from about 0.75 to $1.75 \mu \mathrm{m}$. Note that although the SEM observations are performed under high vacuum and watersolvated ions dehydrate in the SEM chamber, the initially hydrated particles generally appear as larger in the SEM images because of the wettability of the substrate and residues surrounding the particle core as shown in Fig. 10. Therefore, the geometric size of the hydrated particles given by SEM is generally larger than that of dehydrated before sampling. This leads to the conclusion that the shift towards larger sizes of the marine particles during the sea breeze can be due to hygroscopic growth. The number size distributions of dust and mixed dust/marine particle types are also changing during the sea breeze, with both size distributions broadening. Figure $9 \mathrm{c}$ shows the same total number size distributions as in Fig. 9a and b, but normalized to the total number of particles. This presentation facilitates a proper comparison of the distribution shapes and clearly illustrates the shift toward larger particle sizes during the sea breeze. The actual size shift may be even stronger because the SEM analysis provides partially dried aerosol size distributions. Thus, the size underestimation can be due to low thickness of the residues at the border of dehydrated particles. The fact that the sea breeze has an influence on the aerosol size distribution is evident, but the exact explanation can be complex. For instance, a stronger contribution of coarse dust particles can also appear due to local aeolian resuspension of dust caused by the increased surface wind speed. It should also be mentioned that the size-selective dry deposition (Seinfeld and Pandis, 1998) can also take place during the aerosol transport and can have an influence on the size distribution because the wind speed and atmospheric residence time of particles are different before and during the sea breeze. Nevertheless, the observed size shift is in line with the results obtained by remote sensing. In addition, given the relative proportions of particle types, the fraction of hygroscopic particles can be estimated by the cumulative fractions of marine and mixed dust/marine particle types. This cumulative fraction significantly increases from 63 to $88 \%$ in the fine fraction and from 43 to $62 \%$ in the coarse fraction (Fig. 8), which supports the shift toward larger sizes during the sea breeze. Furthermore, the percentage of hygroscopic particles is largely underestimated by an addition of "Marine" and "Mixed Dust/Marine" particle counts, if the fraction of hygroscopic dust was not taken into account. Previous studies reported that mineral dust in the Negev Desert predominantly consists of aluminosilicates and also calcium carbonates (Maenhaut et al., 1999). The solid calcium carbonatecontaining particles can undergo heterogeneous reaction with gaseous nitric acid to form highly hygroscopic calcium nitrate particles. In fact, transformation of non-hygroscopic mineral dust into water-soluble dust has been previously observed in aerosol samples collected in the Negev Desert (Laskin et al., 2005a). In this study, we now subclassify all particles sorted in the "Dust" particle type into five categories: aluminosilicates $\mathrm{AlSi}$, Ca-rich, mixed AlSi/Ca-rich, gypsum, and other AlSi. With an average composition of $\mathrm{Mg}_{0.03} \mathrm{Al}_{0.38} \mathrm{Si}_{1} \mathrm{Fe}_{0.09}$, the predominant subtype was $\mathrm{AlSi}$, accounting for $43.5 \%$ of dust particles, followed by mixed AlSi/Ca-rich particles, representing $34.1 \%$ with an average composition of $\mathrm{Mg}_{0.05} \mathrm{Al}_{0.16} \mathrm{Si}_{0.53} \mathrm{Ca}_{1} \mathrm{Fe}_{0.08}$. The Ca-rich particles represented $17.4 \%$ of dust particles with an average composition of $\mathrm{Mg}_{0.03} \mathrm{Ca}_{1}$ typical of calcium carbonatecontaining minerals (calcite and dolomite). With a frequency of 2.8 and $2.2 \%$ respectively, gypsum particles $\left(\mathrm{S}_{0.75} \mathrm{Ca}_{1}\right)$ and "other $\mathrm{AlSi}$ " $\left(\mathrm{Al}_{0.06} \mathrm{Si}_{0.19} \mathrm{P}_{0.23} \mathrm{~S}_{0.09} \mathrm{Ca}_{0.78} \mathrm{Ti}_{1} \mathrm{Fe}_{0.4}\right)$ were minor subtypes of dust particles, the latter comprising calcium phosphates and TiOx-rich aluminosilicates. To sum up, among the particles sorted in the "Dust" particle type, $\mathrm{Ca}$ rich and mixed $\mathrm{AlSi} / \mathrm{Ca}$-rich particles accounted for $51.5 \%$ and could certainly be considered as hygroscopic dust. Further manual examination of the particles was performed to elucidate the nature of hygroscopic particles.

\subsection{Core-shell particle morphologies observed by SEM/EDX}

Analysis of the SEM/EDX observations also showed a large number of particles surrounded by halos (see particles 

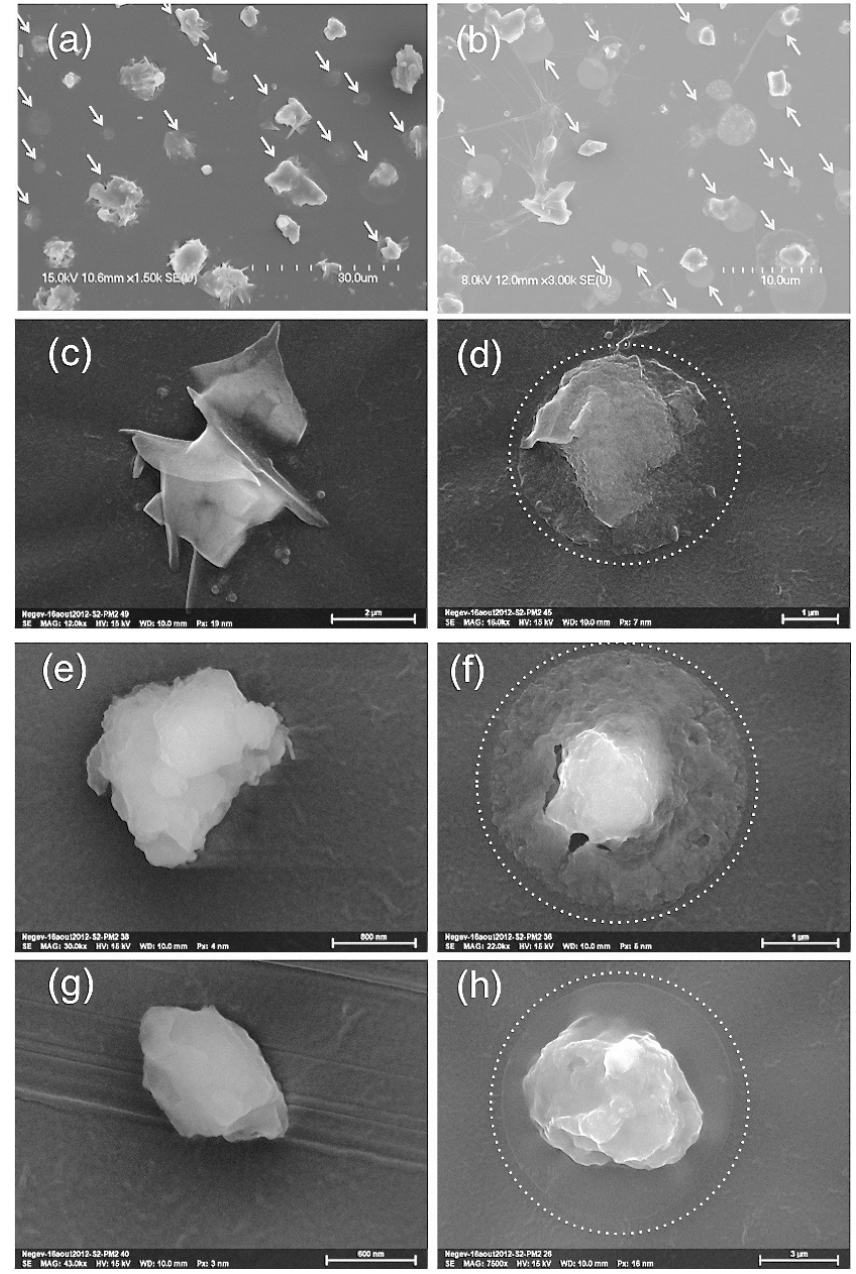

Figure 10. Secondary electron images of (a) particles of the coarse fraction, (b) particles of the fine fraction, (c-h) individual particles typical of (c) fresh marine, (d) aged marine, (e) unreacted dust (silicate), (f) internally mixed dust/marine, (g) unreacted dust (calcite), and (h) aged Ca-rich dust (calcite partly converted to calcium nitrate). Arrows mark the presence of halos. Dotted circles depict the boundaries of halos.

marked by an arrow in Fig. 10a, b). Volatile components and water are lost due to the high-vacuum operating conditions in the SEM chamber and/or during metal coating. As a result, the dry residual compounds form halos around solid cores. This gives direct evidence that the halos consist of residues of a hygroscopic surface layer after dehydration. In our sample, the halos were found on aged deliquescent marine (Fig. 10d), internally mixed dust/marine (Fig. 10f) and dust particles. The presence of halos surrounding some dust particles confirms that the surface of the dust can be covered by potentially hydrophilic layers. The size of such coated dust particles may vary by hygroscopic growth during sea breeze events.

Figure 11 shows elemental maps and EDX spectra of an individual dust (AlSi/Ca-rich) particle with a halo. Calcium
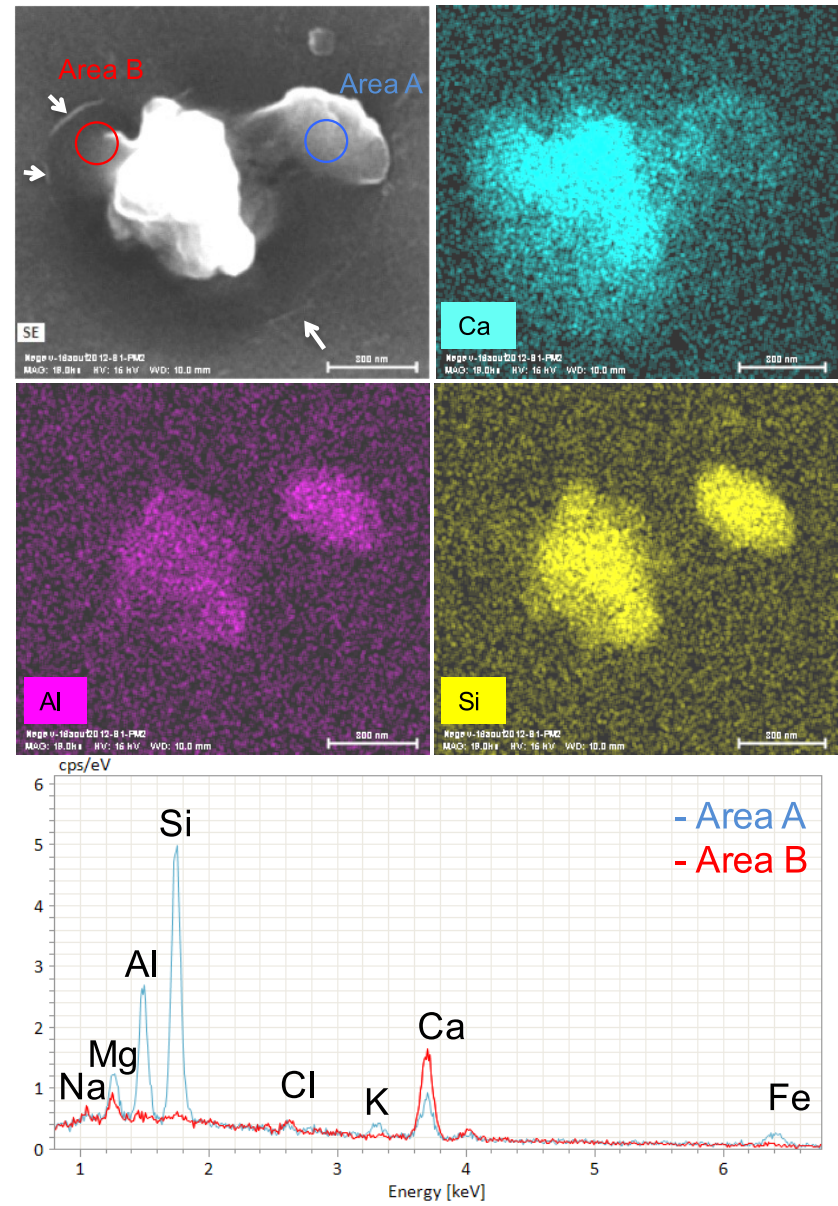

Figure 11. Secondary electron image, elemental energy dispersive $\mathrm{X}$-ray (EDX) mappings ( $\mathrm{Al}, \mathrm{Si}$, and $\mathrm{Ca}$ ), and EDX spectra of an individual internally mixed calcium nitrate/aluminosilicate particle. Scale marker bars correspond to $800 \mathrm{~nm}$. Arrows mark some visible boundaries of a halo.

is relatively more abundant in the halo than in the core, pointing to a probable presence of liquid nitrate coating of dust in the form of calcium nitrate. As particles were collected on polycarbonate membranes, the detection of nitrogen is hampered. To confirm the presence of water-solvated nitrate coatings on some dust particles, complementary analysis was carried out using Raman micro-spectrometry.

\subsection{Raman maps of particles}

Complementary to elemental analysis by SEM/EDX, Raman microspectroscopy distinguishes between solid, deliquescent, and solid inorganic nitrate compounds based on the nitrate band shift. In the liquid state, however, the characteristic nitrate band is identical to those of sodium and calcium nitrate. An example of the Raman molecular mappings is presented in Fig. 12. The spectral map of the $1086 \mathrm{~cm}^{-1}$ peak, attributed to the $\mathrm{CO}_{3}^{2-}$ stretching vibration, illustrates the distribution of calcium carbonate (calcite) within the particles 

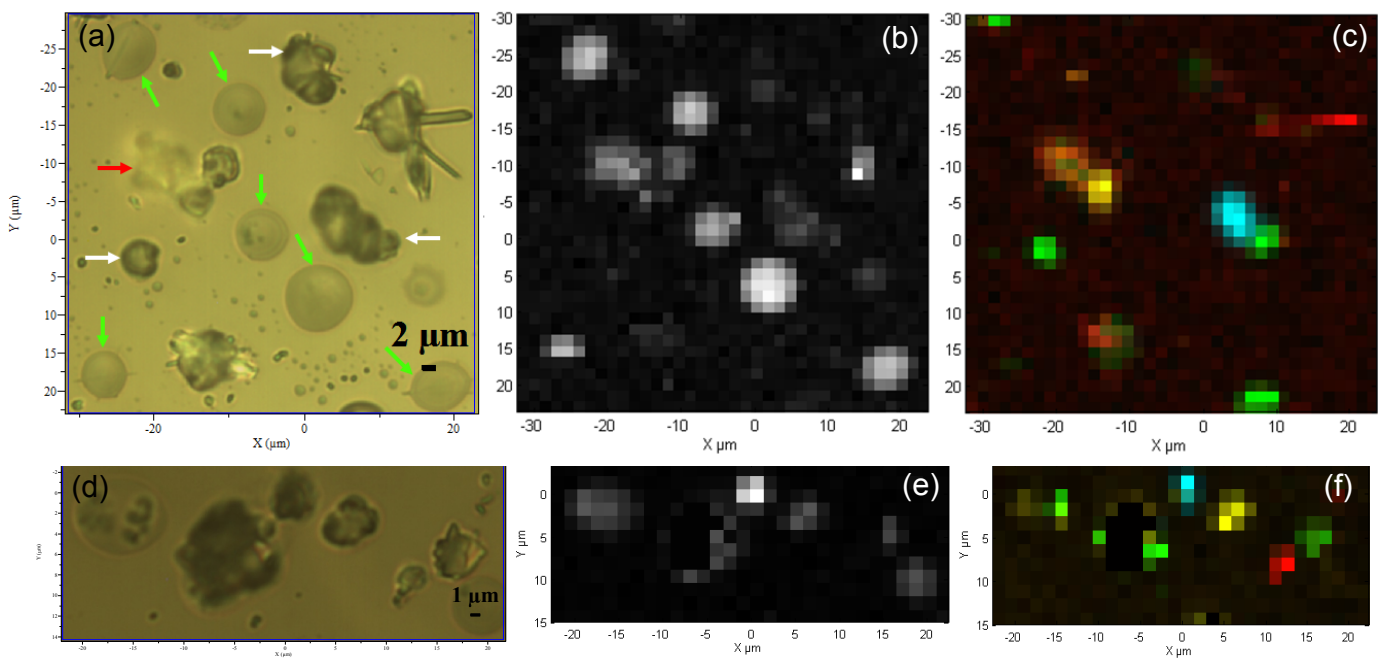

Figure 12. Optical images (a, d) of coarse particles collected before (a-c) and during (d-f) sea breeze and corresponding Raman molecular mappings (b, c, e, f). Raman maps are colored according to the band intensity at $1050 \mathrm{~cm}^{-1}$ (single component maps on the middle panel), and 1068, 1086, 1017, and $993 \mathrm{~cm}^{-1}$ (multi-component overlay maps on the right panel), respectively. White: water-solvated nitrate ion; green: solid sodium nitrate (nitratine); yellow: calcite; cyan: calcium sulfate anhydrite; pink: solid sodium sulfate (thenardite). The meaning of the colored arrows is described in the text.

and is shown in yellow. The spectral map of the $1050 \mathrm{~cm}^{-1}$ peak attributed to the liquid $\mathrm{NO}_{3}^{-}$stretching vibration provides the spatial distribution of water-solvated nitrate and is shown in white. The spectral map of the $993 \mathrm{~cm}^{-1}$ peak assigned to sodium sulfate (thenardite) is reported in pink. The spectral map of the $1017 \mathrm{~cm}^{-1}$ peak characteristic of calcium sulfate anhydrite (recrystallized sea-salt droplets) is depicted in cyan. Finally, the spectral map obtained at $1068 \mathrm{~cm}^{-1}$, indicative of solid sodium nitrate (nitratine), is shown in green. The observed particles consist mainly of $\mathrm{NaNO}_{3}$ solid cores agglomerated with some amount of $\mathrm{Na}_{2} \mathrm{SO}_{4}$ (thenardite) surrounded by a liquid droplet containing $\mathrm{NO}_{3}^{-}$ions. These particles, marked with white arrows in Fig. 12, were classified as sea salts when observed by SEM/EDX. Numerous particles are also formed as a mixture of solid $\mathrm{NaNO}_{3}, \mathrm{CaSO}_{4} \cdot 2 \mathrm{H}_{2} \mathrm{O}$ and liquid nitrate ion (an example marked by a red arrow in Fig. 12). They were classified as mixed dust/sea-salt particles when analyzed by SEM/EDX. Generally, sodium nitrate particles partially recrystallize during analysis due to local heating under the laser beam. The remaining particles probably contain Raman inactive $\mathrm{NaCl}$ and undetected species. Furthermore, Raman analysis is conducted at $\sim 60 \% \mathrm{RH}$. It is remarkable that some particles remain with a droplet shape (marked by green arrows in Fig. 12). This points to a probable presence of calcium nitrate with very low deliquescence RH in the range of 10-18\% (Laskin et al., 2005a; Tang et al., 2016). Thus, these Ca-rich particles may have been collected as droplets. They were classified as dust particles when examined by SEM/EDX.

\section{The impact of the sea breeze on the aerosol radiative effect}

In this section, we evaluate the impact of the sea breeze on the broadband solar radiation, through perturbation of the aerosol properties. The diurnal variability in the solar radiative flux at the Earth's surface generally follows a monotonic and smooth curve as a function of time or solar zenith angle, if the sky is clear and the atmospheric conditions are stable. Perturbations of the solar flux can appear due to the presence of clouds or to changes in aerosol characteristics. In Fig. 13a, we present the solar flux at the surface as a function of time, which is measured by the pyranometer of SolRadNet for the afternoon of 16 August. An irregular drop in the solar flux occurs at 14:00 UTC, which is the time of arrival of the sea breeze front. The discontinuity in the slope implies a loss of solar energy received at the surface presumably due to changes in the aerosol properties or atmospheric water vapor content. To evaluate the sea-breeze-induced radiative effect, we calculated the solar fluxes and the net instantaneous direct aerosol radiative effect using a computational tool described in Derimian et al. (2016). Note that the calculated solar flux is for the wavelength range of $0.2-4.0 \mu \mathrm{m}$, while the measured is for $0.3-2.8 \mu \mathrm{m}$, which implies about $3 \%$ bias due to the cut-off of the spectral range (the accuracy of the measurements themselves is about 3-5\% as well). Nevertheless, this discrepancy in the spectral ranges does not affect analysis of the relative perturbation of the solar flux when evaluated using the measurements or the calculations separately. The calculations of the solar flux employ the aerosol models retrieved by AERONET and the parameters of the gaseous con- 
centrations and surface reflectance at the site for 16 August that are adopted from the database of the AERONET operational code. The results of the simulated solar flux are superimposed on the results of the measurements in Fig. 13b and are presented as a function of the corresponding solar zenith angles. The fluxes that are calculated for the aerosol characteristics retrieved just before (red line) and during (blue line) the sea breeze are in good agreement with the measurements and the magnitude of the drop in the measured flux. Thus, the difference between the red and the blue lines, for the same solar zenith angle, corresponds to the loss of solar energy reaching the surface due to the sea breeze. For example, at a solar zenith angle of $60^{\circ}$, which corresponds to the time of the sea breeze front, the reduction of the solar flux is about $23 \mathrm{~W} \mathrm{~m}^{-2}$. This amounts to $4.6 \%$ reduction of the total solar flux that would reach the surface without the sea breeze effect. It should be realized, however, that the reduction in the solar flux is not only due to the change in aerosol properties but also due to the increase in the water vapor content. In order to estimate the role of each component, additional calculations were conducted assuming that only the increase in the water vapor takes place, and then assuming that only the aerosol properties change. The results show that the increase in the water vapor (from 1.62 to $2.13 \mathrm{~g} \mathrm{~cm}^{-2}$ ) is responsible for a loss of $7.5 \mathrm{~W} \mathrm{~m}^{-2}$ in the solar flux reaching the surface, while the change in the aerosol properties is responsible for $15.5 \mathrm{~W} \mathrm{~m}^{-2}$ of the total $23 \mathrm{~W} \mathrm{~m}^{-2}$ difference, which amounts to 1.5 and $3.1 \%$, respectively. We now evaluate the aerosol instantaneous net direct radiative effect, which is defined as the difference between downwelling and upwelling fluxes at a given atmospheric layer in aerosol-free and aerosol-laden conditions. The instantaneous radiative effect refers to a value at a particular solar zenith angle. The radiative effect is formulated so that a negative sign signifies a radiative cooling. Thus, a negative value at the bottom of atmosphere signifies a radiative cooling at the surface. At the top of the atmosphere, a negative value signifies additionally reflected radiation due to aerosol presence and therefore a radiative cooling of the whole surface-atmosphere system. More details about the calculation tool and approach used can be found in Derimian et al. (2016). Figure 13c and $\mathrm{d}$ present the calculated instantaneous net aerosol radiative effect at the bottom and the top of the atmosphere before and during sea breeze. For example, before the sea breeze the background aerosol produces a radiative effect of up to about $-10 \mathrm{~W} \mathrm{~m}^{-2}$ at the ground and $-5 \mathrm{~W} \mathrm{~m}^{-2}$ at the top of the atmosphere. Then, the negative aerosol radiative effect increases during the sea breeze up to $-20.5 \mathrm{~W} \mathrm{~m}^{-2}$ at the ground and $-6.6 \mathrm{~W} \mathrm{~m}^{-2}$ at the top of the atmosphere. We can therefore estimate a doubling of the aerosol radiative cooling effect at the surface and an increase by almost one-third at the top of the atmosphere due to the sea breeze effect on this specific day. The difference between the net top and net bottom radiative effects is the atmospheric radiative effect. It represents the part of the energy that is trapped in the atmosphere
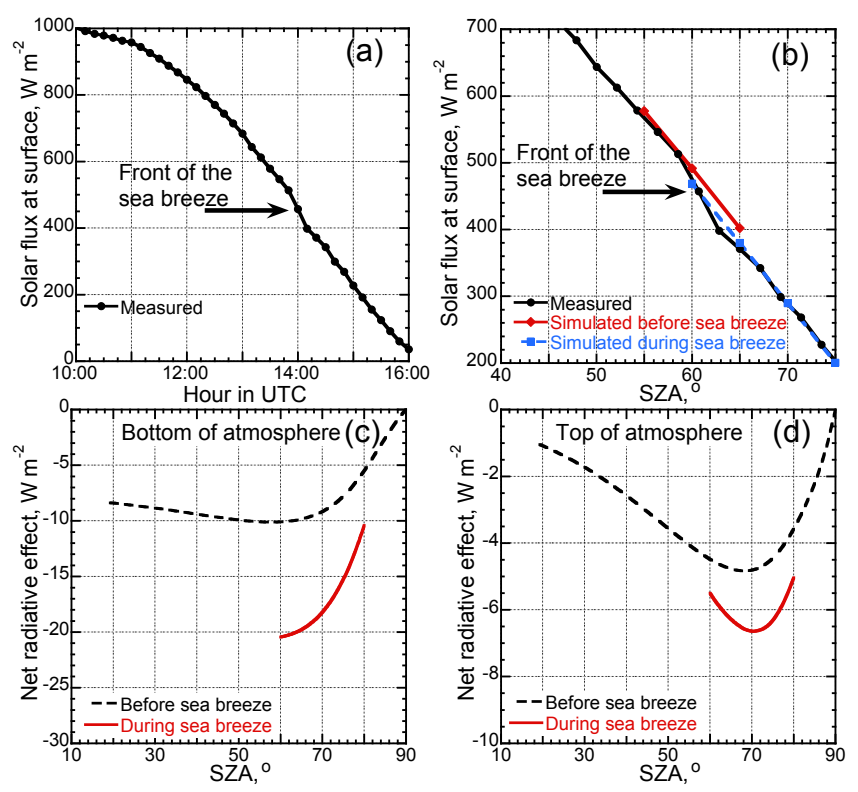

Figure 13. (a) Downwelling solar flux measured at the surface by the pyranometer of SolRad-Net in the afternoon of 16 August. (b) Measured solar flux and results of the flux simulations based on the AERONET retrievals of aerosol characteristics just before and during the sea breeze. (c, d) Net aerosol radiative effect calculated before and during the sea breeze at the bottom and the top of the atmosphere. The measured flux is presented in panel (a) as a function of time and in panels (b-d) as a function of the corresponding solar zenith angles (SZA).

due to the aerosol presence. The atmospheric radiative effect is always positive and represents the radiative warming of the atmospheric layer. The atmospheric radiative effect increases during the sea breeze by almost 3 times, that is, from about $5 \mathrm{~W} \mathrm{~m}^{-2}$ before the sea breeze to about $14 \mathrm{~W} \mathrm{~m}^{-2}$ during the sea breeze. We therefore can conclude that the sea-breezeinduced changes in the aerosol characteristics can lead to an important relative change in the background aerosol radiative effect.

\section{Aerosol core-shell structure and implication for remote sensing}

As follows from the individual particle analysis presented in Sect. 5, coatings of particles by a liquid layer are quite probable even in locations believed to be dominated by hydrophobic aerosols. At the same time, only a homogeneous particle model is used in remote sensing algorithms. Generally, the reason for this is a lack of sensitivity of the remote sensing measurements to detailed aerosol microphysical characteristics. In this section, we attempt to verify the possible impact of the core-shell structure on the aerosol microphysical parameters retrieved using the homogeneous particle assumption in the AERONET operational algorithm. We 
also discuss the implications for other types of remote sensing measurements, motivated by the possibility that particles with complex microphysics can provide optical characteristics that are hard to reproduce using a homogeneous particle model. Indeed, it is also possible that the aerosol microphysical characteristics retrieved using the homogeneity assumption will be an equivalent that satisfies the radiative properties of more complex microphysics. The question that we therefore examine is, how can the core-shell structure affect the retrieved aerosol spectral complex refractive index, volume size distribution, and fractions of spherical-nonspherical aerosols if a homogeneous particle model is assumed in the retrievals? It should be mentioned here that, with respect to the AERONET retrievals, Dubovik et al. (2000) already provided a test of the effect of internal (core-shell) mixture on the retrieved aerosol microphysical parameters using a simple model of black carbon core and water-soluble substance shell. Tests were also performed for the possible effects of external mixture and the assumption of aerosol sphericity as part of the accuracy assessment of aerosol optical properties retrievals from AERONET. It is noteworthy that, because the aerosol sphericity assumption was found to cause artifacts, the randomly oriented spheroids model was introduced in the retrieval algorithms (Dubovik et al., 2006). However, the tests of Dubovik et al. (2000) for the influence of external and internal (core-shell structure) aerosol mixture on the retrievals did not show anomalies in the retrieved size distribution, while the retrieved real and imaginary parts of the complex refractive index yielded equivalent values that were generally in between the refractive indexes of the components constituting the mixture.

In the current study, we first conduct the forward calculation of the directional aerosol optical properties of homogeneous and core-shell particles reflecting our observations in the Negev Desert. They are then inverted using the same inversion scheme as AERONET in order to verify the applicability of the conclusions in Dubovik et al. (2000) to our case study. We also analyze a case where the phase function across the full angular range is available for the retrievals. Note that the calculations presented here are performed in a single-scattering approximation and not for radiances as they would be observed by a sun/sky photometer and as presented in Dubovik et al. (2000). The reasoning is that if the differences are not significant in a single-scattering case, then they will be diminished even more in the case of multiple scattering under real atmospheric conditions.

Three simplified scenarios are considered: first, the particles are homogeneous spheres, and second and third, a liquid water layer coats the particles with a thickness that corresponds to 10 and $40 \%$ of the total particle radius, respectively. This percentage is assumed because, at a thickness of about $10 \%$, the differences in optical characteristics become notable and for about $40-50 \%$ the residual of the fit in the inversion procedure reaches a maximum. This indicates the largest discrepancy between the core-shell model and the particle homogeneity assumption as used in the inversion. The percentage used here can be putted in the context of real observations by converting to widely used geometric hygroscopic growth factor, which is the ratio between humidified and dry particle diameter. Thus, $10 \%$ corresponds to a growth factor of 1.11 , which can be defined as a low to moderate value, and $40 \%$ corresponds to 1.67 , which is near the upper limit of values in the review by Swietlicki et al. (2008), for instance. It is noteworthy that our tests show important differences in optical characteristics and increased residuals of fit also for 30 and $20 \%$ shell thickness. In fact, the effect of the coating also depends on the shape of the particle size distribution and the contrast in refractive indexes of core and shell; therefore, the subject merits some more detailed studies. In the forward calculations of the presented work, the complex refractive index of the core is assumed to be $1.47+0.003 i$, which is based on the values obtained for the aerosol model before the sea breeze; it is also assumed to be spectrally independent for simplicity. The assumed complex refractive index of the shell is $1.33+0.0 i$, the value for pure water, and is also assumed to be spectrally independent. The refractive index used in the case of homogeneous particles is the same as that of the core. It is important to note that the total particle radius is kept constant in all three scenarios in order to rule out the effects of changing aerosol size distribution. In the case of the coated particles, the size of the core is therefore decreased proportionally.

Figure $14 \mathrm{a}$ and $\mathrm{b}$ present the forward-calculated spectral aerosol optical thickness and the directional distribution of scattered light intensity $\left(P 11(\theta) \cdot\right.$ AOT $\left._{\text {scat }}\right)$ that are further used for the inversion, employing a conventional homogeneous particle model; panel (c) illustrates the directional distribution of the degree of linear polarization $(-P 12(\theta) / P 11(\theta))$ of the scattered light, with $\mathrm{AOT}_{\text {scat }}$ being the aerosol optical thickness for scattering and $P 11(\theta)$ and $P 12(\theta)$ being elements of the scattering matrix, where $P 11(\theta)$ fulfills the normalization condition of

$$
\frac{1}{2} \int_{0}^{\pi} P 11(\theta) \cdot \sin \theta \mathrm{d} \theta=1 \text {. }
$$

Note that $P 11(\theta)$ is calculated for scattering angles from 0 to $180^{\circ}$ with a resolution of $1^{\circ}$, which represents an ideal possible scenario of measurements. The wavelengths employed for the spectral AOT and $P 11(\theta) \cdot$ AOT $_{\text {scat }}$ are 440, 670, 870, and $1020 \mathrm{~nm}$, which are the operational wavelengths of the AERONET retrievals.

The spectral AOT presented in Fig. 14a is normalized to the maximum value in order to show the variability in spectral dependence due to the coating. A change in the spectral AOT and the angular dependence of $P 11(\theta) \cdot$ AOT $_{\text {scat }}$ (Fig. 14a and b) is perceptible for the case of $10 \%$ and is significant for the case of $40 \%$ shell thickness. In order to evaluate the impact on the retrieved microphysical param- 

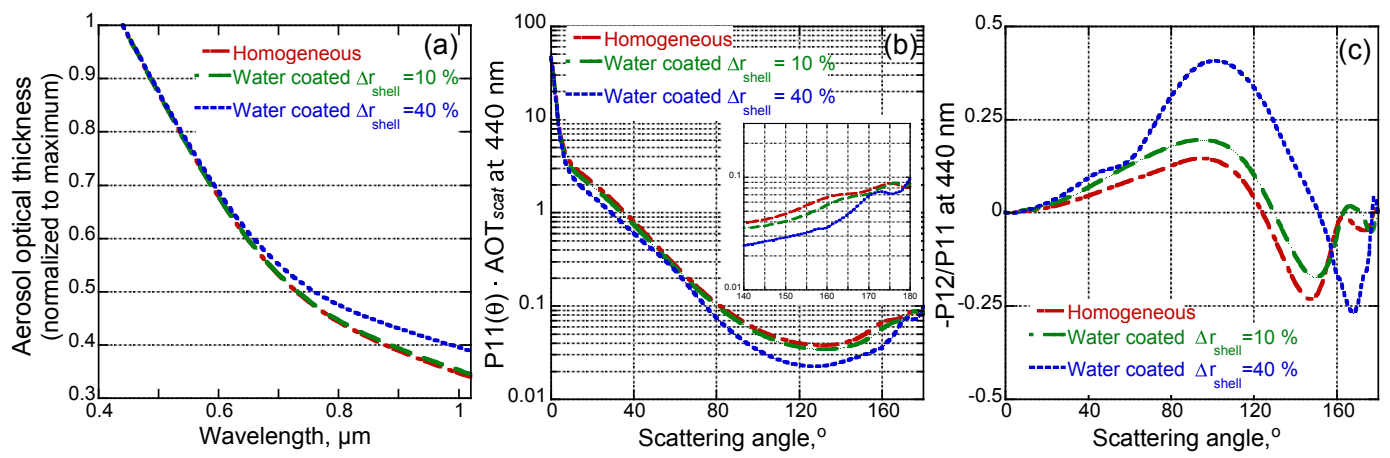

Figure 14. (a) Spectral aerosol optical thickness (AOT), (b) phase function at $440 \mathrm{~nm}$, and (c) degree of linear polarization at $440 \mathrm{~nm}$ calculated under the assumption of spherical homogeneous and coated particles, where the coating thickness is 10 and $40 \%$ of the total particle radius. The calculated characteristics are for an aerosol size distribution observed during the sea breeze and complex refractive index of core and shell as described in the text; the refractive index for the homogeneous case is equal to that of the core value. The presented AOTs are normalized to the maximum value.
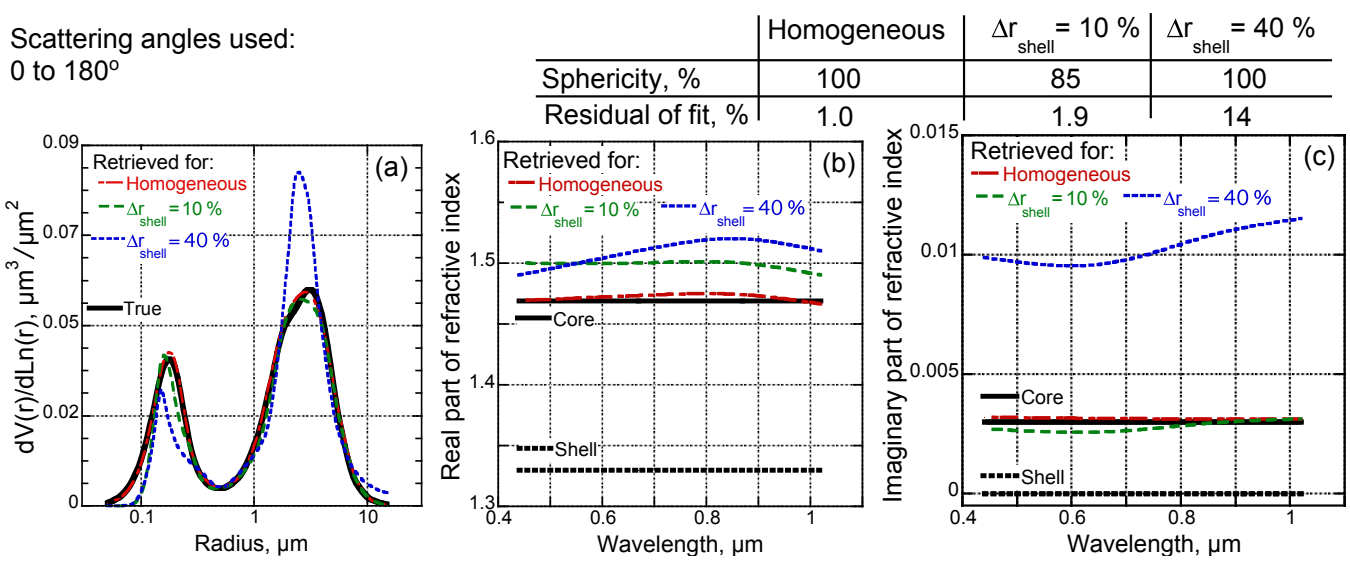

Figure 15. (a) Aerosol size distributions, (b) real, and (c) imaginary part of the complex refractive indexes as assumed in the forward calculations of the aerosol optical characteristics (labeled "True", "Core", "Shell") and as a result of the inversion of the optical characteristics of homogeneous and core-shell particles presented in Fig. 14. The inserted table summarizes the retrieved percentage of spherical particles and the residual error between the assumed and the fitted aerosol optical characteristics. The results are obtained for the case when the scattering angle of the phase function ranges from 0 to $180^{\circ}$.

eters, we now invert simultaneously the spectral AOT and $P 11(\theta) \cdot \mathrm{AOT}_{\text {scat }}$.

For the case when the forward calculations are conducted using the homogeneous aerosol model, the inversion procedure reproduces very well the assumed aerosol size distribution, the real and imaginary part of the complex refractive index, and the fraction of spherical particles (Fig. 15, homogeneous case). The homogeneous scenario is an initial and necessary test, which illustrates first of all the consistency of the calculations and secondly that accurate characteristics can be retrieved with spectral AOT and full angular range phase function. In the case of forward calculations conducted for a $10 \%$ coating thickness, the retrieved real refractive index is greater than that of the core, a discrepancy appears in the sphericity fraction, and the residual of the fit increases (see inserted table in Fig. 15). The most important disagreement appears in the case of $40 \%$ coating thickness. The retrieved refractive indexes significantly exceed those of the core, and a quite different size distribution is required in order to fit the spectral AOT and the phase function using a homogeneous particle model. It is expected that, in the case of mixed aerosol, the values of the retrieved refractive index will be in between the refractive indexes of the two components. The facts that the retrieved values are greater and that the size distribution is modified suggest that the inversion algorithm attempts to compensate for the specific particle morphology by an exceptional aerosol model. Note that the residual error of the fit is as high as of $14 \%$, in contrast to 1 or $1.9 \%$ in the two previous scenarios, indicating the difficulty to obtain an accurate reproduction of the spectral AOT and the full angular range phase function. It follows that, at least for the case considered here, the core-shell particle structure can have characteristics that are difficult to reproduce by an equivalent homogeneous aerosol model. As can be seen from Fig. 14b, the 
Scattering angles used: 0 to $120^{\circ}$

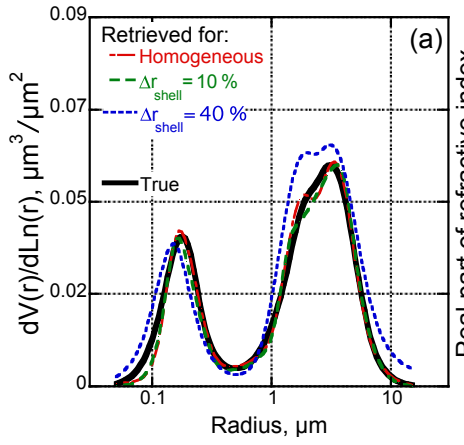

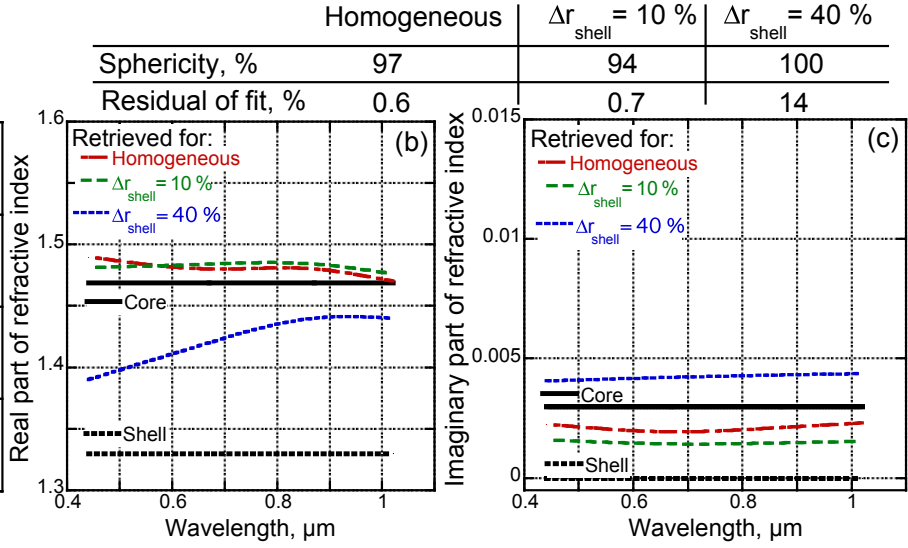

Figure 16. Same as Fig. 15 but for the range of scattering angles from 0 to $120^{\circ}$.

main differences in the phase function of a core-shell aerosol relative to a homogeneous one are in the backward scattering angles. However, ground-based photometers cannot observe backward-scattered light and measure the radiation scattered mostly in the forward direction - up to about $120^{\circ}$ of the scattering angle, depending on the sun elevation angle during almucantar measurements. In order to mimic the AERONET angular observations range, we conduct calculations for the phase function in the angular range from 0 to $120^{\circ}$. By limiting the angular range we clearly lose sensitivity and, in the case of homogeneous particles, the real and imaginary refractive indexes are now not as well retrieved as with the full range of the scattering angles (red line in Fig. 16b, c versus in Fig. 15b, c). However, the values are still comparable to the originally assumed values - i.e., those of the core. The scenario of $10 \%$ coating thickness provides results very similar to the homogeneous case. A difference, however, appears for the scenario of $40 \%$, when the real refractive index is clearly in between the refractive indexes of the dust core and water shell components. It is noteworthy that the result is consistent with the tendency observed at the Sede Boker site, i.e., the real refractive index decreases as the water vapor concentration increases. Also notable is the appearance of a similar spectral dependence of the real refractive index as in the case of high water vapor content, i.e., lower values at shorter wavelengths. This can be due to a stronger sensitivity of the radiation at shorter wavelengths to the shell material on the surface of the particle, whereas radiation at longer wavelengths is more influenced by the internal part of the particle. The imaginary refractive index becomes greater than the one of core, a tendency that is also visible in the observations. The residual of the fit is quite high, which means that a physical interpretation of the retrieved microphysical parameters should be advanced with caution. In addition, retrievals with high residuals are generally screened in final products and therefore cases where the aerosol morphology differs drastically from the morphology assumed in the retrieval algorithms may be omitted. However, the obtained high residuals show that the measurements have sensitivity to the core-shell structure. That is, it appears that a homogeneous particles model is not able to reproduce accurately the characteristics of the core-shell structure. Similar conclusions can also be drawn for the case of the inversion of the phase function over the full angular range. Additionally, Fig. $14 \mathrm{c}$ presents a not yet discussed variability in the degree of linear polarization. This deviation of the degree of linear polarization from the homogeneous particle scenario is even stronger than that of the phase function. For instance, there is even a sign reversal in the peak at a scattering angle of about $170^{\circ}$ in the case of $40 \%$ coating thickness. The results of our tests (not shown here as graphs) of a simultaneous inversion of spectral AOT, $P 11(\theta) \cdot \mathrm{AOT}_{\text {scat }}$, and $-P 12(\theta) / P 11(\theta)$ show similar tendencies of increasing the residual error of the fit and aberrant refractive index and size distribution as the thickness of the coating increases. Thus, an even stronger sensitivity to the core-shell structure is expected if polarization is measured.

It can be concluded that, in some measurement configurations, an equivalent homogeneous particle model can indeed represent the optical characteristics of a liquid coating even under the assumption of a single-scattering approximation. This conclusion is in general agreement with the results of Dubovik et al. (2000); however, we can also conclude that including backward scattering angles and polarimetric measurements present more sensitivity to the core-shell structure. This is because the main differences, due to the aerosol core-shell structure, are observed in the angular and polarimetric characteristics of the light scattered in the backward angles. Thus, since the backward scattering is a primary signal measured by satellites and lidar, important implications for these types of measurements are possible. For example, the aerosol core-shell structure will affect the lidar ratio and a parameterized core-shell aerosol model can be considered in satellites retrievals. 


\section{Conclusions}

The influence of the sea breeze on the atmospheric aerosol chemical composition, microphysical, optical, and radiative characteristics in the Negev Desert of Israel during summertime is shown for the first time and discussed in detail. We employed extensive remote sensing observations, in situ aerosol sampling and laboratory physicochemical characterization of the particles. We found that, at an arid location inland at a distance of at least $80 \mathrm{~km}$ from the Mediterranean seashore, marine aerosol particles and air masses are influencing daily the desert aerosol composition. While the entire phenomenon lasts for about $3 \mathrm{~h}$, an abrupt increase and a peak in aerosol size, volume concentration, and optical thickness, as derived by AERONET observations in the solar spectrum, occur with the arrival of the sea breeze front. Simultaneously, the sky brightness temperature, derived by radiometric measurements in the thermal infrared spectrum, also increases and shows a weaker spectral dependence, which indicates a contribution of large aerosol particles and/or water droplets (the former behaves like a black body in TIR). The effect of the sea breeze front on the atmospheric radiative characteristics was most obvious in the measurements by the thermal infrared radiometer. This illustrates the great potential of the simultaneous and complementary observations of solar and thermal infrared radiances for aerosol studies.

We found that the fraction of hygroscopic marine and internally mixed dust/marine aerosol particles increases significantly during the sea breeze; however, similar particles are present as a background in the Negev Desert also before the sea breeze arrival. The increase in atmospheric water vapor content and relative humidity is associated with the sea breeze arrival; thus, the aerosol size distributions show a shift towards larger particles. We suggest that hygroscopic growth can explain the observed shift in the aerosol size distribution. This hypothesis is supported by SEM/EDX analyses, which show that a large number of particles are surrounded by liquid residuals. Despite the desert location of the site, we also found that a large fraction of the sampled particles is composed of highly hygroscopic material. Although particles of all sizes grew, the size shift of the fine mode was stronger (see Fig. 6). This can be linked to the size-dependent aerosol composition, which shows higher fractions of hygroscopic particles in $\mathrm{PM}_{1}$, consisting of marine and internal dust/marine mixtures. We also observed that many dust particles had a liquid coating in the form of water-solvated nitrate. These nitrates have an anthropogenic origin and their internal mixture with dust, namely Ca-rich particles, makes dust highly hygroscopic; the point of deliquescence of such particles can be at RH values as low as about 10 to $20 \%$. Thus, even in a dry desert environment, such dust particles can contain a substantial amount of liquid water, as was also observed in our samples. These results are also in line with the decreasing values of the AERONET-retrieved real refractive index, indicating a presence of water in the aerosol composition. The observed liquid coating of particles can have more general implications for the modeling of the aerosol scattering and absorption properties. This is because all present-day remote sensing algorithms for the retrieval of aerosol microphysical properties assume homogeneous particles. Indeed, there are practical reasons for this assumption related to issues of measurement sensitivity, as discussed in Sect. 7. Based on the numerical simulations presented here we suggest that a sensitivity of remote sensing to the core-shell structure exists in those observational configurations where information about the phase function in an extended angular range and polarimetric measurements are used, and that scattering in the backward directions is particularly important.

In addition to the individual particle microphysics, the sea breeze also perturbs the radiative budget. On a specific day, 16 August 2012, we estimated $4.6 \%$ reduction in the broadband solar radiation reaching the surface due to the sea breeze, where $1.5 \%$ is due to increase in the water vapor content and $3.1 \%$ is due to the change in aerosol concentration and microphysics. The background net aerosol radiative cooling was doubled at the surface and increased by about one-third at the top of the atmosphere. The atmospheric radiative warming, which is the difference between the net top and the net bottom radiative effects, increased by about a factor of 3. The cooling of the surface and the warming of the atmospheric layer can change the gradient of the atmospheric temperature profile, which may imply a feedback on the sea breeze dynamic; this subject merits a separate dedicated study.

This study illustrates the complexity of the aerosol microphysics when marine, desert, and pollution air masses interact. An understanding and proper modeling of aerosol optical properties in coastal areas should be of high importance because densely populated and industrial centers are frequently located on the seashores. The sea breeze occurs in many locations around the world and this systematic phenomenon can be used as a natural laboratory to study and evaluate the impact of the aerosol mixing state and hygroscopicity on aerosol optical properties and radiation.

Data availability. Data from the ground-based meteorological station, the integrating nephelometer measurements, the laboratory analysis of sampled aerosol, and results of the numerical simulations are available upon request to the corresponding author (yevgeny.derimian@univ-lille1.fr). The air mass backward trajectory, AERONET, MPLNET, and SolRad-Net data are available from http://ready.arl.noaa.gov/HYSPLIT_traj.php, https://aeronet. gsfc.nasa.gov/index.html, https://mplnet.gsfc.nasa.gov, and http:// solrad-net.gsfc.nasa.gov, respectively. Quick looks of the thermal infrared radiometer data are visible at http://www-loa.univ-lille1. fr/index.php/observation/sites.html and the data are available upon request from the corresponding author. 
Competing interests. The authors declare that they have no conflict of interest.

Acknowledgements. The CaPPA project (Chemical and Physical Properties of the Atmosphere) is funded by the French National Research Agency (ANR) through the PIA (Programme d'Investissement d'Avenir) under contract "ANR-11-LABX-000501" and by the Regional Council "Nord Pas de Calais - Picardie" and the European Funds for Regional Economic Development (FEDER). The SEM facility in Lille (France) is supported by the Conseil Regional du Nord-Pas de Calais and the European Regional Development Fund (ERDF). Alexander Laskin acknowledges support from the W.R. Wiley Environmental Molecular Sciences Laboratory (EMSL), a national scientific user facility located at PNNL, and sponsored by the Office of Biological and Environmental Research of the US DOE. PNNL is operated for the US DOE by the Battelle Memorial Institute under contract no. DEAC06-76RL0 1830. The MPLNET project is funded by the NASA Radiation Sciences Program and Earth Observing System. We thank the MPLNET PIs Ellsworth Judd Welton and Sebastian A. Stewart for their effort in establishing and maintaining the Sede Boker site. The authors gratefully acknowledge the NOAA Air Resources Laboratory (ARL) for the provision of the HYSPLIT transport and dispersion model and the READY website (http://ready.arl.noaa.gov) used in this publication. Special thanks to Alexander Goldberg from the Jacob Blaustein Institute for Desert Research, Ben Gurion University, Sede Boker Campus, for highly valuable technical help, which enabled the proper functioning of the instrumentation at the site. We also thank Abraham Zangvil and David Klepach from the same institution for providing the meteorological data. We finally thank the anonymous reviewers for their thoughtful reading and for suggesting additional conclusions.

Edited by: Nikolaos Mihalopoulos

Reviewed by: three anonymous referees

\section{References}

Andreae, T. W., Andreae, M. O., Ichoku, C., Maenhaut, W., Cafmeyer, J., Karnieli, A., and Orlovsky, L.: Light scattering by dust and anthropogenic aerosol at a remote site in the Negev desert, Israel, J. Geophys. Res.-Atmos., 107, 4008, doi:10.1029/2001JD900252, 2002.

Brogniez, G., Pietras, C., Legrand, M., Dubuisson, P., and Haeffelin, M.: A high-accuracy multiwavelength radiometer for in situ measurements in the thermal infrared. Part II: Behavior in field experiments, J. Atmos. Ocean. Tech., 20, 1023-1033, https://doi.org/10.1175/15200426(2003)20<1023:ahmrfi>2.0.co;2, 2003.

Campbell, J. R., Hlavka, D. L., Welton, E. J., Flynn, C. J., Turner, D. D., Spinhirne, J. D., Scott, V. S., and Hwang, I. H.: Full-time, eye-safe cloud and aerosol lidar observation at atmospheric radiation measurement program sites: Instruments and data processing, J. Atmos. Ocean. Tech., 19, 431-442, https://doi.org/10.1175/15200426(2002)019<0431:ftesca>2.0.co;2, 2002.
Choël, M., Deboudt, K., Osán, J., Flament, P., and Van Grieken, R.: Quantitative determination of low-Z elements in single atmospheric particles on boron substrates by automated scanning electron microscopy - Energy-dispersive X-ray spectrometry, Anal. Chem., 77, 5686-5692, https://doi.org/10.1021/ac050739x, 2005.

Dayan, U. and Rodnizki, J.: The temporal behavior of the atmospheric boundary layer in Israel, J. Appl. Meteorol., 38, 830-836, 1999.

Deboudt, K., Flament, P., Choël, M., Gloter, A., Sobanska, S., and Colliex, C.: Mixing state of aerosols and direct observation of carbonaceous and marine coatings on African dust by individual particle analysis, J. Geophys. Res.-Atmos., 115, D24207, https://doi.org/10.1029/2010jd013921, 2010.

Dentener, F. J., Carmichael, G. R., Zhang, Y., Lelieveld, J., and Crutzen, P. J.: Role of mineral aerosol as a reactive surface in the global troposphere, J. Geophys. Res.-Atmos., 101, 22869 22889, https://doi.org/10.1029/96jd01818, 1996.

Derimian, Y., Karnieli, A., Kaufman, Y. J., Andreae, M. O., Andreae, T. W., Dubovik, O., Maenhaut, W., Koren, I., and Holben, B. N.: Dust and pollution aerosols over the Negev desert, Israel: Properties, transport, and radiative effect, J. Geophys. Res.Atmos., 111, D05205, https://doi.org/10.1029/2005JD006549, 2006.

Derimian, Y., Dubovik, O., Huang, X., Lapyonok, T., Litvinov, P., Kostinski, A. B., Dubuisson, P., and Ducos, F.: Comprehensive tool for calculation of radiative fluxes: illustration of shortwave aerosol radiative effect sensitivities to the details in aerosol and underlying surface characteristics, Atmos. Chem. Phys., 16, 5763-5780, https://doi.org/10.5194/acp-16-5763-2016, 2016.

Draxler, R. R. and Hess, G. D.: An overview of the Hysplit_4 modeling system for trajectories, Aust. Met. Mag., 47, 295-308, 1998.

Dubovik, O. and King, M. D.: A flexible inversion algorithm for retrieval of aerosol optical properties from Sun and sky radiance measurements, J. Geophys. Res.-Atmos., 105, 20673-20696, 2000.

Dubovik, O., Smirnov, A., Holben, B. N., King, M. D., Kaufman, Y. J., Eck, T. F., and Slutsker, I.: Accuracy assessments of aerosol optical properties retrieved from Aerosol Robotic Network (AERONET) Sun and sky radiance measurements, J. Geophys. Res.-Atmos., 105, 9791-9806, https://doi.org/10.1029/2000jd900040, 2000.

Dubovik, O., Holben, B., Eck, T. F., Smirnov, A., Kaufman, Y. J., King, M. D., Tanre, D., and Slutsker, I.: Variability of absorption and optical properties of key aerosol types observed in worldwide locations, J. Atmos. Sci., 59, 590-608, 2002.

Dubovik, O., Sinyuk, A., Lapyonok, T., Holben, B. N., Mishchenko, M., Yang, P., Eck, T. F., Volten, H., Munoz, O., Veihelmann, B., van der Zande, W. J., Leon, J.-F., Sorokin, M., and Slutsker, I.: Application of spheroid models to account for aerosol particle nonsphericity in remote sensing of desert dust, J. Geophys. Res.Atmos., 111, D11208, https://doi.org/10.1029/2005jd006619, 2006.

Eck, T. F., Holben, B. N., Reid, J. S., Dubovik, O., Smirnov, A., O'Neill, N. T., Slutsker, I., and Kinne, S.: Wavelength dependence of the optical depth of biomass burning, urban, and desert dust aerosols, J. Geophys. Res.-Atmos., 104, 31333 31349, https://doi.org/10.1029/1999jd900923, 1999. 
Eck, T. F., Holben, B. N., Sinyuk, A., Pinker, R. T., Goloub, P., Chen, H., Chatenet, B., Li, Z., Singh, R. P., Tripathi, S. N., Reid, J. S., Giles, D. M., Dubovik, O., O’Neill, N. T., Smirnov, A., Wang, P., and Xia, X.: Climatological aspects of the optical properties of fine/coarse mode aerosol mixtures, J. Geophys. Res.Atmos., 115, D19205, https://doi.org/10.1029/2010jd014002, 2010.

Eilers, P. H. C.: A perfect smoother, Anal. Chem., 75, 3631-3636, https://doi.org/10.1021/ac034173t, 2003.

Eilers, P. H. C. and Boelens, H. F. M.: Baseline correction with asymmetric least squares smoothing, Leiden University Medical Centre report, 2005.

Falkovich, A. H., Schkolnik, G., Ganor, E., and Rudich, Y.: Adsorption of organic compounds pertinent to urban environments onto mineral dust particles, J. Geophys. Res.-Atmos., 109, D02208, https://doi.org/10.1029/2003jd003919, 2004.

Formenti, P., Andreae, M. O., Andreae, T. W., Ichoku, C., Schebeske, G., Kettle, J., Maenhaut, W., Cafmeyer, J., Ptasinsky, J., Karnieli, A., and Lelieveld, J.: Physical and chemical characteristics of aerosols over the Negev Desert (Israel) during summer 1996, J. Geophys. Res.-Atmos., 106, 4871-4890, 2001.

Holben, B. N., Eck, T. F., Slutsker, I., Tanre, D., Buis, J. P., Setzer, A., Vermote, E., Reagan, J. A., Kaufman, Y. J., and Nakajima, T.: AERONET - A federated instrument network and data archive for aerosol characterization, Remote. Sens. Environ., 66, 1-16, 1998.

Ichoku, C., Andreae, M. O., Andreae, T. W., Meixner, F. X., Schebeske, G., Formenti, P., Maenhaut, W., Cafmeyer, J., Ptasinski, J., Karnieli, A., and Orlovsky, L.: Interrelationships between aerosol characteristics and light scattering during late winter in an Eastern Mediterranean arid environment, J. Geophys. Res.Atmos., 104, 24371-24393, 1999.

Karnieli, A., Derimian, Y., Indoitu, R., Panov, N., Levy, R. C., Remer, L. A., Maenhaut, W., and Holben, B. N.: Temporal trend in anthropogenic sulfur aerosol transport from central and eastern Europe to Israel, J. Geophys. Res.-Atmos., 114, D00D19, https://doi.org/10.1029/2009JD011870, 2009.

Krueger, B. J., Grassian, V. H., Laskin, A., and Cowin, J. P.: The transformation of solid atmospheric particles into liquid droplets through heterogeneous chemistry: Laboratory insights into the processing of calcium containing mineral dust aerosol in the troposphere, Geophys. Res. Lett., 30, 1148, https://doi.org/10.1029/2002g1016563, 2003.

Krueger, B. J., Grassian, V. H., Cowin, J. P., and Laskin, A.: Heterogeneous chemistry of individual mineral dust particles from different dust source regions: the importance of particle mineralogy, Atmos. Environ., 38, 6253-6261, https://doi.org/10.1016/j.atmosenv.2004.07.010, 2004.

Laskin, A., Iedema, M. J., Ichkovich, A., Graber, E. R., Taraniuk, I., and Rudich, Y.: Direct observation of completely processed calcium carbonate dust particles, Faraday Discuss., 130, 453-468, https://doi.org/10.1039/b417366j, 2005a.

Laskin, A., Wietsma, T. W., Krueger, B. J., and Grassian, V. H.: Heterogeneous chemistry of individual mineral dust particles with nitric acid: A combined CCSEM/EDX, ESEM, and ICP-MS study, J. Geophys. Res.-Atmos., 110, D10208, https://doi.org/10.1029/2004jd005206, 2005b.

Legrand, M., Pietras, C., Brogniez, G., Haeffelin, M., Abuhassan, N. K., and Sicard, M.: A high-accuracy multiwave- length radiometer for in situ measurements in the thermal infrared. Part I: Characterization of the instrument, J. Atmos. Ocean. Tech., 17, 1203-1214, https://doi.org/10.1175/15200426(2000)017<1203:ahamrf>2.0.co;2, 2000.

Levin, Z., Ganor, E., and Gladstein, V.: The effects of desert particles coated with sulfate on rain formation in the eastern Mediterranean, J. Appl. Meteorol., 35, 1511-1523, 1996.

Levin, Z., Teller, A., Ganor, E., and Yin, Y.: On the interactions of mineral dust, sea-salt particles, and clouds: A measurement and modeling study from the Mediterranean Israeli Dust Experiment campaign, J. Geophys. Res.-Atmos., 110, D20202, doi10.1029/2005JD005810, 2005.

Li, J., Posfai, M., Hobbs, P. V., and Buseck, P. R.: Individual aerosol particles from biomass burning in southern Africa: 2, Compositions and aging of inorganic particles, J. Geophys. Res.-Atmos., 108, 8484, https://doi.org/10.1029/2002jd002310, 2003.

Maenhaut, W., Cafmeyer, J., Ptasinski, J., Andreae, M. O., Andreae, T. W., Elbert, W., Meixner, F. X., Karnieli, A., and Ichoku, C.: Chemical composition and light scattering of the atmospheric aerosol at a remote site in the Negev Desert, Israel, J. Aerosol Sci., 28, S73-S74, 1997.

Maenhaut, W., Ptasinski, J., and Cafmeyer, J.: Detailed mass size distributions of atmospheric aerosol species in the Negev desert, Israel, during ARACHNE-96, Nucl. Instrum. Meth. B, 150, 422427, 1999.

Maenhaut, W., Karnieli, A., and Andreae, M. O.: Ten-year study of fine aerosol at Sde Boker, Israel, using PIXE: Time trends, seasonal variation, correlations, and source areas for anthropogenic elements, Nucl. Instrum. Meth. B., 318, 119-124, https://doi.org/10.1016/j.nimb.2013.05.092, 2014.

Marjamaki, M., Keskinen, J., Chen, D. R., and Pui, D. Y. H.: Performance evaluation of the electrical low-pressure impactor (ELPI), J. Aerosol Sci., 31, 249-261, https://doi.org/10.1016/s00218502(99)00052-x, 2000.

Navea, J. G., Chen, H. H., Huang, M., Carmichel, G. R., and Grassian, V. H.: A comparative evaluation of water uptake on several mineral dust sources, Environ. Chem., 7, 162-170, https://doi.org/10.1071/en09122, 2010.

Reid, J. S., Jonsson, H. H., Maring, H. B., Smirnov, A., Savoie, D. L., Cliff, S. S., Reid, E. A., Livingston, J. M., Meier, M. M., Dubovik, O., and Tsay, S. C.: Comparison of size and morphological measurements of coarse mode dust particles from Africa, J. Geophys. Res.-Atmos., 108, 8593, doi10.1029/2002JD002485, 2003.

Seinfeld, J. H. and Pandis, S. N.: Atmospheric Chemistry and Physics: From Air Pollution to Climate Change, John Wiley \& Sons, Inc., New York, 49, 1998.

Sobanska, S., Coeur, C., Maenhaut, W., and Adams, F.: SEM-EDX characterisation of tropospheric aerosols in the Negev desert (Israel), J. Atmos. Chem., 44, 299-322, 2003.

Spinhirne, J., Berkoff, T., Welton, E., and Campbell, J.: High pulse repetition rate, eye safe, visible wavelength lidar systems: Design, results and potential, IGARSS 2002: IEEE International Geoscience and Remote Sensing Symposium and 24th Canadian Symposium on Remote Sensing, Vols. I-VI, Proceedings: Remote Sensing: Integrating Our View of the Planet, IEEE, New York, 1382-1383, 2002. 
Spinhirne, J. D., Rall, J. A. R., and Scott, V. S.: Compact eye safe Lidar systems, Review of Laser Engineering, 23, 112-118, https://doi.org/10.2184/lsj.23.112, 1995.

Tang, M. J., Cziczo, D. J., and Grassian, V. H.: Interactions of water with mineral dust aerosol: water adsorption, hygroscopicity, cloud condensation, and ice nucleation, Chem. Rev., 116, 42054259, https://doi.org/10.1021/acs.chemrev.5b00529, 2016.

Usher, C. R., Michel, A. E., and Grassian, V. H.: Reactions on mineral dust, Chem. Rev., 103, 4883-4939, https://doi.org/10.1021/cr020657y, 2003.

Welton, E. J. and Campbell, J. R.: Micropulse lidar signals: uncertainty analysis, J. Atmos. Ocean. Tech., 19, 2089-2094, https://doi.org/10.1175/15200426(2002)019<2089:mlsua>2.0.co;2, 2002.
Welton, E. J., Campbell, J. R., Spinhirne, J. D., and Scott, V. S.: Global monitoring of clouds and aerosols using a network of micro-pulse lidar systems, in: Lidar Remote Sensing for Industry and Environment Monitoring, edited by: Singh, U. N., Itabe, T., and Sugimoto, N., Proceedings of the Society of Photo-Optical Instrumentation Engineers (Spie), Spie-Int Soc Optical Engineering, Bellingham, 151-158, 2001.

Wielicki, B. A., Cess, R. D., King, M. D., Randall, D. A., and Harrison, E. F.: Mission to planet earth - role of clouds and radiation in climate, B. Am. Meteorol. Soc., 76, 2125-2153, https://doi.org/10.1175/1520 0477(1995)076<2125:mtpero>2.0.co;2, 1995. 